\title{
Recent Advances on Boosting the Cell Voltage of Aqueous Supercapacitors
}

Cite as

Nano-Micro Lett.

(2020) 12:98

Received: 18 January 2020

Accepted: 18 March 2020

Published online: 20 April 2020

(C) The Author(s) 2020

\author{
Qianzhi Gou ${ }^{1}$, Shuang Zhao ${ }^{1}$, Jiacheng Wang ${ }^{1}$, Meng Li $^{1} \bowtie$, Junmin Xue ${ }^{2}$ \\ Qianzhi Gou and Shuang Zhao contributed equally to this work. \\ $\square$ Meng Li, limeng@cqu.edu.cn \\ 1 MOE Key Laboratory of Low-Grade Energy Utilization Technologies and Systems, CQU-NUS Renewable \\ Energy Materials and Devices Joint Laboratory, School of Energy and Power Engineering, Chongqing \\ University, Chongqing 400044, People's Republic of China \\ 2 Department of Materials Science and Engineering, CQU-NUS Renewable Energy Materials and Devices \\ Joint Laboratory, National University of Singapore, Singapore 117573, Singapore
}

\section{HIGHLIGHTS}

- High-voltage aqueous supercapacitors hold promise for commercial energy storage devices due to the excellent electrochemical performance.

- This review summarizes the efficacious measures on boosting the cell voltage of aqueous supercapacitors from the aspects of electrode, electrolyte, and asymmetric design.

\begin{abstract}
Due to its ultra-fast charge/discharge rate, long cyclic life span, and environmental benignity, aqueous supercapacitor (SC) is considered as a proper nextgeneration energy storage device. Unfortunately, limited by undesirable water electrolysis and unreasonable electrode potential range, aqueous SC normally generates a narrow cell voltage, resulting in a low energy density. To address such challenge, enormous efforts have been made to construct high-voltage aqueous SCs. Despite these achievements, the systematic reviews about this field are still rare. To fill this knowledge gap, this review summarizes the recent advances about boosting the cell voltage of aqueous SCs. From the viewpoint of electrode, doping alkali cations, modulating the electrode mass ratio, and optimizing the surface charge density are regarded as three effective pathways to achieve this goal. However, adjusting the appropriate $\mathrm{pH}$ level, introducing redox mediators, and constructing "water-in-salt" electrolyte are other three universal routes from the electrolyte aspect. Furthermore, it is also effective to obtain the high-voltage aqueous SCs through asymmetric design,

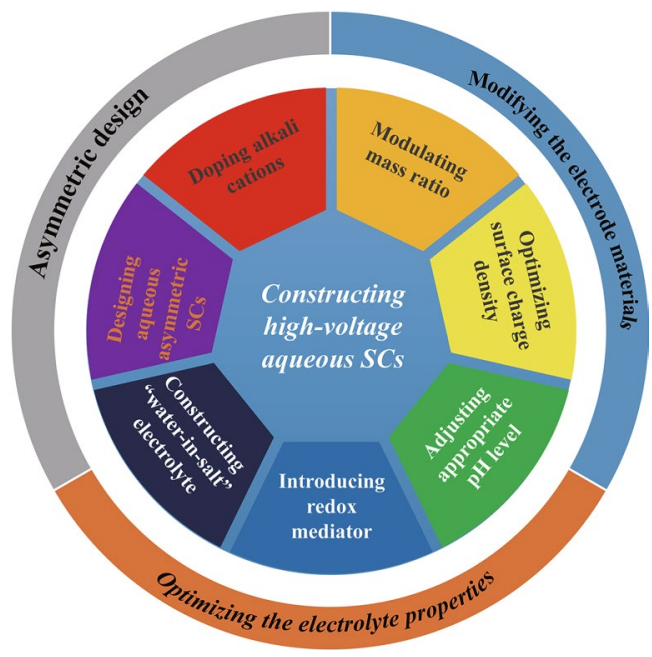
such as designing asymmetric SCs. The confronting challenges and future development tendency towards the high-voltage aqueous SCs are further discussed.
\end{abstract}

KEYWORDS Aqueous supercapacitors; Cell voltage; Electrodes; Electrolytes; Asymmetric design 


\section{Introduction}

With the consumption of traditional fossil fuels, the everincreasing energy depletion crisis and environmental pollution issues have drawn tremendous attentions in the past decades. To mitigate the aforesaid dilemma, it is urgent to develop numerous sustainable and renewable energy conversion and energy storage devices, such as secondary batteries [1, 2], supercapacitors (SCs) [3, 4], and fuel cells [5]. Among them, SCs, also named electrochemical capacitor, is recognized as an attractive candidate for next-generation energy storage systems, ascribed to its rapid charge/ discharge rate, high power density, long cycling lifespan, favorable safety, and environmental benignity [6]. Similar to the majority of electrochemical energy storage devices, traditional commercial SCs are primarily composed of the positive electrode, negative electrode, electrolyte, current collector, and separator (Fig. 1a) [7, 8]. Based on the diverse energy storage mechanisms, SCs can be mainly classified into electrochemical double-layer capacitors (EDLCs) and pseudo-capacitors (PCs) (Fig. 1b, c) [7, 9, 10]. In principle, the charge storage mechanism of EDLCs is the electrostatic interaction at the interface between electrode and electrolyte, whereas PCs utilize the fast and reversible faradaic redox reactions to store charges [11]. Moreover, SCs can also be categorized into symmetric SCs (two identical electrodes) and ASCs (two dissimilar electrodes) according to the distinct structural configurations. Although great achievements have been obtained in pursuit of high performance SCs, the insufficient energy density is still hampering their practical applications (Fig. 1d) [12]. To satisfy the ever-increasing requirements of energy storage, it is desirable to establish the SC devices with high energy density.

According to the equation of energy density for SCs $\left(E=0.5 C V^{2}\right)$, the value of energy density $(E)$ is directly determined by specific capacitance $(C)$ and cell voltage $(V)$. (a)
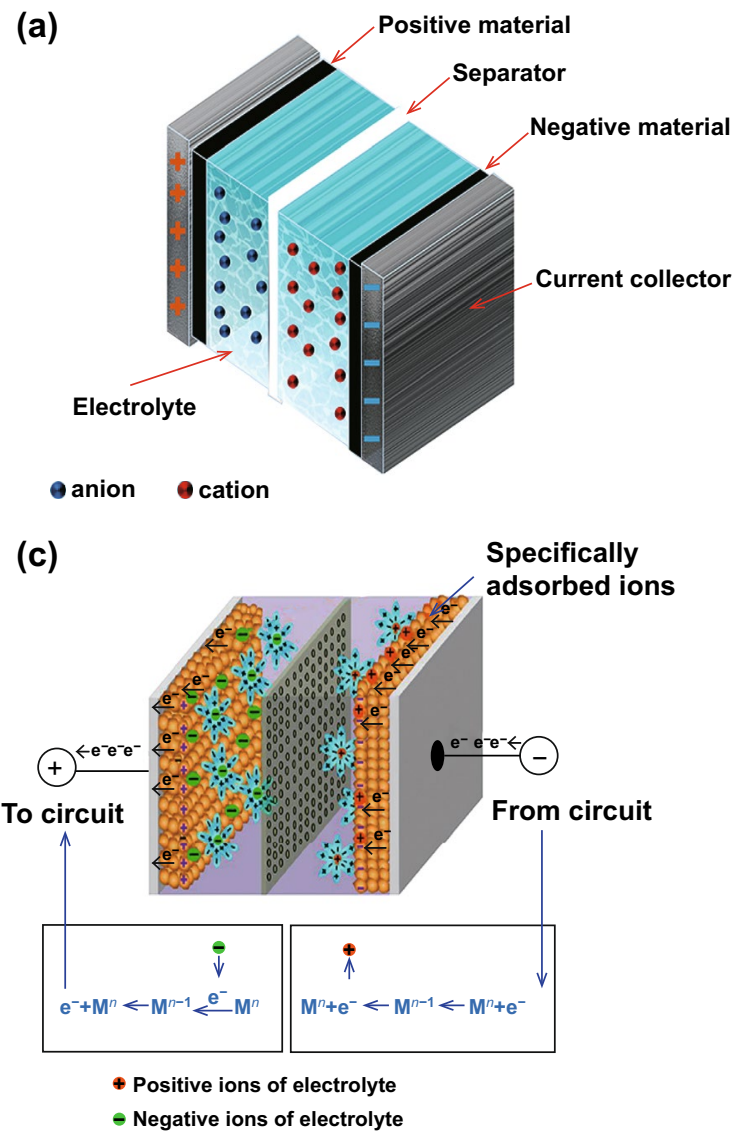

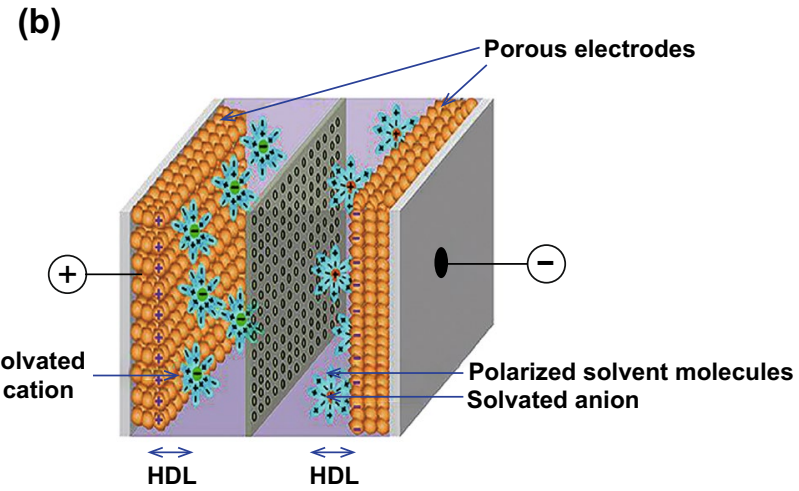

(d)

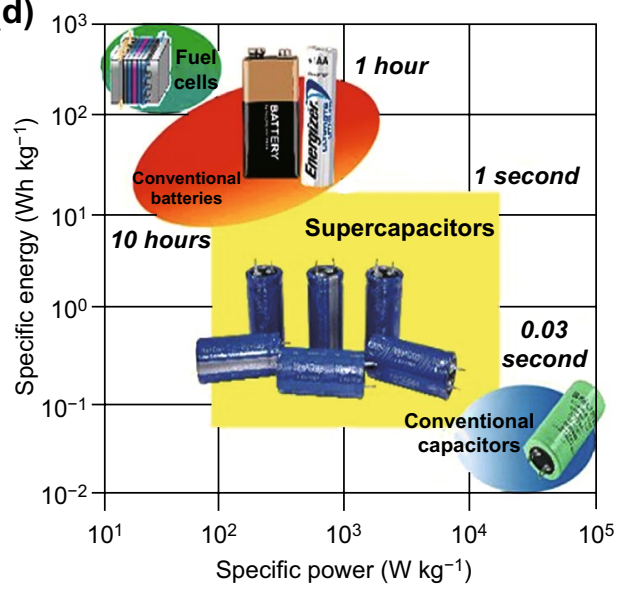

Fig. 1 a Schematic of an intact SC device. b Charge storage mechanisms of EDLCs and PCs. c Charge storage of PCs. Adapted with permission from Ref. [10]. d Specific power versus specific energy plot for various types of energy storage devices. Adapted with permission from Ref. [12] 
Up to now, enormous research hot spots mainly focus on how to design high specific capacitance electrode materials (e.g., carbon-based materials $[4,13]$, transition metal oxides $[6,14]$, conducting polymers $[15,16]$, and sulfides $[17,18]$ etc.), but neglect the other promising direction. In comparison with specific capacitance, energy density is proportional to the square of cell voltage $\left(V^{2}\right)$. Hence, it is more efficient to enhance the energy density of SCs via increasing the value of $V[19,20]$. It is well known that the cell voltage is principally determined by the electrochemical stability window (ESW) of electrolyte [21]. Therefore, the major strategy to increase the cell voltage of aqueous SCs is selecting the electrolyte with a wide ESW [22]. At present, organic electrolyte is widely applied to assemble high-voltage SCs due to its high electrolysis resistance [23]. Nevertheless, the characteristics of inferior ionic conductivity, high flammability and volatility, toxicity as well as expensive price are the dominating shortcomings that restrict its practical prospects $[24,25]$. Furthermore, although the SC device operating in organic electrolyte is able to deliver an enhanced energy density, the relatively high equivalent series resistance and low ion diffusion rate are still its fatal shortcomings which may sacrifice the additional power density $\left(P=V^{2} / 4 R_{\mathrm{S}}\right.$, where $P, V$, and $R_{\mathrm{S}}$ refer to power density, cell voltage, and equivalent inner resistance of the SC device, respectively) [26]. Therefore, it is desirable to search for more appropriate electrolytes to displace the organic electrolytes.

Among various candidates, aqueous electrolyte is re-considered as a proper substitute for organic electrolyte owing to its intriguing features, such as superior conductivity, low cost, high mobility, prominent safety, nontoxicity, and environmental benignity $[9,27]$. The relevant works about aqueous SCs have received substantial attentions in recent years. Nevertheless, the practical applications of aqueous SCs are still inhibited by two major bottlenecks. One is the narrow ESW of aqueous media. As we all know, the thermodynamic stable potential range of $\mathrm{H}_{2} \mathrm{O}$ is only $1.23 \mathrm{~V}$. When the applied potential is out of this value, $\mathrm{H}_{2}$ will be released on the surface of negative electrode resulting from the occurrence of hydrogen evolution reaction (HER), whereas $\mathrm{O}_{2}$ will be released on the positive electrode surface originating from oxygen evolution reaction (OER) process [21]. Along with these reactions, the actual ESW of aqueous media is normally lower than $1.23 \mathrm{~V}$ which may reduce the cell voltage of integrated device. Aiming at the above phenomenon, improving the over-potential of HER and OER under the steady state of electrode can efficiently solve this problem [26]. The other is the unsuitable electrode potential range. Owing to the different storage energy mechanisms, positive electrode and negative electrode possess their separate potential range [28]. When they are assembled as an intact aqueous SCs, the cell voltage is dictated by two electrodes. Unfortunately, limited by the unused potential region and electrocatalytic activity of electrodes in aqueous media, the cell voltage of integrated device is unequal to the sum of the theoretical potential ranges of both electrodes [29, 30]. Based on the aforesaid considerations, a great deal of efforts has been made to overcome these challenges, such as optimizing the features of electrodes, extending the ESW of electrolyte, and designing aqueous ASCs [20, 25, 31]. Despite these great achievements, the number of systematic reviews about boosting the cell voltage of aqueous SCs is still rare in recent years. Hence, the purpose of this mini review is to fill this knowledge gap.

Through further surveying and summarizing the domestic and overseas research works, it can be concluded that modifying the electrode materials, optimizing the electrolyte properties, and designing asymmetric devices are regarded as three dominant and efficient strategies to acquire the high-voltage aqueous SCs. On this basis, this mini review is mainly divided into three sections and further expanded by detailed: (1) doping alkali cations, modulating the electrode mass ratio, and optimizing the surface charge density are three generic pathways from the aspect of electrodes; (2) adjusting the appropriate $\mathrm{pH}$ level, introducing redox mediators, and constructing "water-in-salt" (WIS) electrolyte are three universal methods from the viewpoint of electrolyte; (3) designing aqueous ASCs is an attractive pathway to widen the cell voltage from the device configuration aspect. The confronting challenges and development trends towards highvoltage aqueous SCs will be further discussed and forecasted.

\section{Modifying the Electrode Materials}

The narrow cell voltage is a major obstacle that inhibits the development of aqueous SCs with high energy density. Considering the importance of electrodes, it is a feasible pathway to enlarge the cell voltage via modifying the electrodes materials [29, 32, 33]. Moreover, based on the various energy storage mechanisms, electrode materials can mainly be grouped into electric double-layer capacitive electrodes 
and pseudo-capacitive electrodes [34]. Among them, the former stores energy through the electrostatic interaction between the electrode and electrolyte, such as carbon-based materials, whereas the latter utilizes the fast and reversible redox reactions to store pseudo-capacitances, such as transition-metal compounds and conducting polymers [35, 36]. Up to now, tremendous attempts have been made to assemble the high-voltage aqueous SCs via modifying these two type electrodes, such as doping alkali cations, modulating the electrode mass ratio, and optimizing the surface charge density. On this basis, the relevant mechanisms and research status about aforesaid approaches are introduced and discussed in the following sections.

\subsection{Doping Alkali Cations}

Recently, doping alkali cations $\left(\mathrm{Li}^{+}, \mathrm{Na}^{+}\right.$, and $\left.\mathrm{K}^{+}\right)$into electrode materials is recognized as an efficacious strategy to extend the cell voltage of aqueous SCs [22, 31]. In principle, alkali cations exhibit various reaction mechanisms in different type electrode materials. Taking manganese oxide $\left(\mathrm{MnO}_{2}\right)$ as a typical case, due to its charming properties of high specific capacitance, luxuriant reserves, environmental friendliness, low OER activity, and well-established fabrication methods, $\mathrm{MnO}_{2}$ is regarded as an ideal pseudocapacitive electrode for aqueous SCs [37, 38]. When alkali cations are inserted into $\mathrm{MnO}_{2}$ framework, they can stabilize the polymorph structure, enhance cyclic stability, offer extra capacitance, and facilitate the ion diffusion process [39-42]. More importantly, alkali cations can also efficiently inhibit the electrocatalytic activity of $\mathrm{MnO}_{2}$ electrode in aqueous electrolyte because of the competitive relationship between alkali cations intercalation process and OER [31, 43]. For example, Jabeen et al. fabricated a hierarchical architecture of Birnessite $\mathrm{Na}_{0.5} \mathrm{MnO}_{2}$ nanosheet assembled nanowall arrays (NWAs) in situ grown on carbon cloth via an electrochemical oxidation method (Fig. 2a) [31]. Benefiting from the existence of $\mathrm{Na}^{+}$, the potential range of as-prepared $\mathrm{Na}_{0.5} \mathrm{MnO}_{2}$ NWAs electrode can be enlarged to $0-1.3 \mathrm{~V}$ (vs. $\mathrm{Ag} / \mathrm{AgCl}$ ) in a three-electrode system. To complement this electrode, carbon-coated $\mathrm{Fe}_{3} \mathrm{O}_{4}\left(\mathrm{Fe}_{3} \mathrm{O}_{4} @ \mathrm{C}\right)$ nanorods arrays were synthesized as anode and presented a stable potential range of $1.3-0 \mathrm{~V}$ (vs. $\mathrm{Ag} / \mathrm{AgCl}$ ). Benefiting from the smart electrode modification and unique fabrication methods, this $\mathrm{Na}_{0.5} \mathrm{MnO}_{2} / / \mathrm{Fe}_{3} \mathrm{O}_{4} @ \mathrm{C}$ aqueous ASC with $1 \mathrm{M} \mathrm{Na}_{2} \mathrm{SO}_{4}$ as the electrolyte can demonstrate a maximum cell voltage of $2.6 \mathrm{~V}$ (Fig. 2b, c).

Similarly, doping alkali cations is also suitable for extending the potential range of electric double-layer capacitive electrodes. As a representative for such electrodes, carbonbased materials have a long studying history in the area of aqueous SCs due to their favorable conductivity, superior chemical stability, inferior HER activity, and low cost [13, 44]. In general, carbonaceous electrodes normally possess the features of high specific surface area and porous structure, thus inevitably resulting in a mass of residual heteroatoms ( $\mathrm{N}$ and $\mathrm{O}$ ) on their surface which originated from the high temperature pyrolysis of organics and biomass in insert atmosphere [28, 45]. However, the existence of such heteroatoms is a double-edged sword. On the one hand, these heteroatoms can enhance electrical conductivity, offer abundant active sites, and accelerate the rate of electrochemical reactions. On the other hand, they can also improve the activity of HER and promote water electrolysis process. In view of this, doping alkali cations into carbonbased electrode can validly eliminate this scruple. When alkali cations are adsorbed on the defect positions of heteroatoms, they can not only keep the intrinsic advantages of heteroatoms, but also serve as physical barrier for $\mathrm{H}^{+}$ adsorption via an electrostatic repulsion behavior, thereby suppressing the activity of HER (Fig. 2d) [46, 47]. Recently, Xiong et al. employed an electroreduction method to fabricate electrochemically reduced porous carbon (ERPC) electrode in $1 \mathrm{M} \mathrm{Na}_{2} \mathrm{SO}_{4}$ solution [43]. It is notable that the electrochemical reduction technique enables $\mathrm{Na}^{+}$to be adsorbed on the defect atom sites of the carbon-based materials through a thermodynamically favorable process. Owing to the physical barrier behavior of $\mathrm{Na}^{+}$, the potential range of this ERPC electrode was expanded to 1.4-0 V (vs. saturated calomel electrode, SCE). To simultaneously boost the potential range of positive electrode, they also inserted $\mathrm{Na}^{+}$intoMnO $\mathrm{Mn}_{2}$ electrode $\left(\mathrm{Na}_{0.25} \mathrm{MnO}_{2}\right)$ via a facile electrochemical oxidation technique, which delivered a wide potential range of $0-1.3 \mathrm{~V}$ (vs. SCE). When both electrodes were assembled as a standard $\mathrm{Na}_{0.25} \mathrm{MnO}_{2} / /$ ERPC aqueous ASC device, this system was able to display a high cell voltage of $2.7 \mathrm{~V}$ (Fig. 2e). Motivated by the above studies, Wu et al. fabricated a $2.7 \mathrm{~V}$ aqueous ASC device which applied the Na-adsorbed graphene aerogels thin slice on the carbon cloth substrate (Na-FG-CC) as the negative electrode and the Na-adsorbed carbon layer coated $\mathrm{Mn}_{3} \mathrm{O}_{4}\left(\mathrm{C} @ \mathrm{Mn}_{3} \mathrm{O}_{4}\right)$ as 

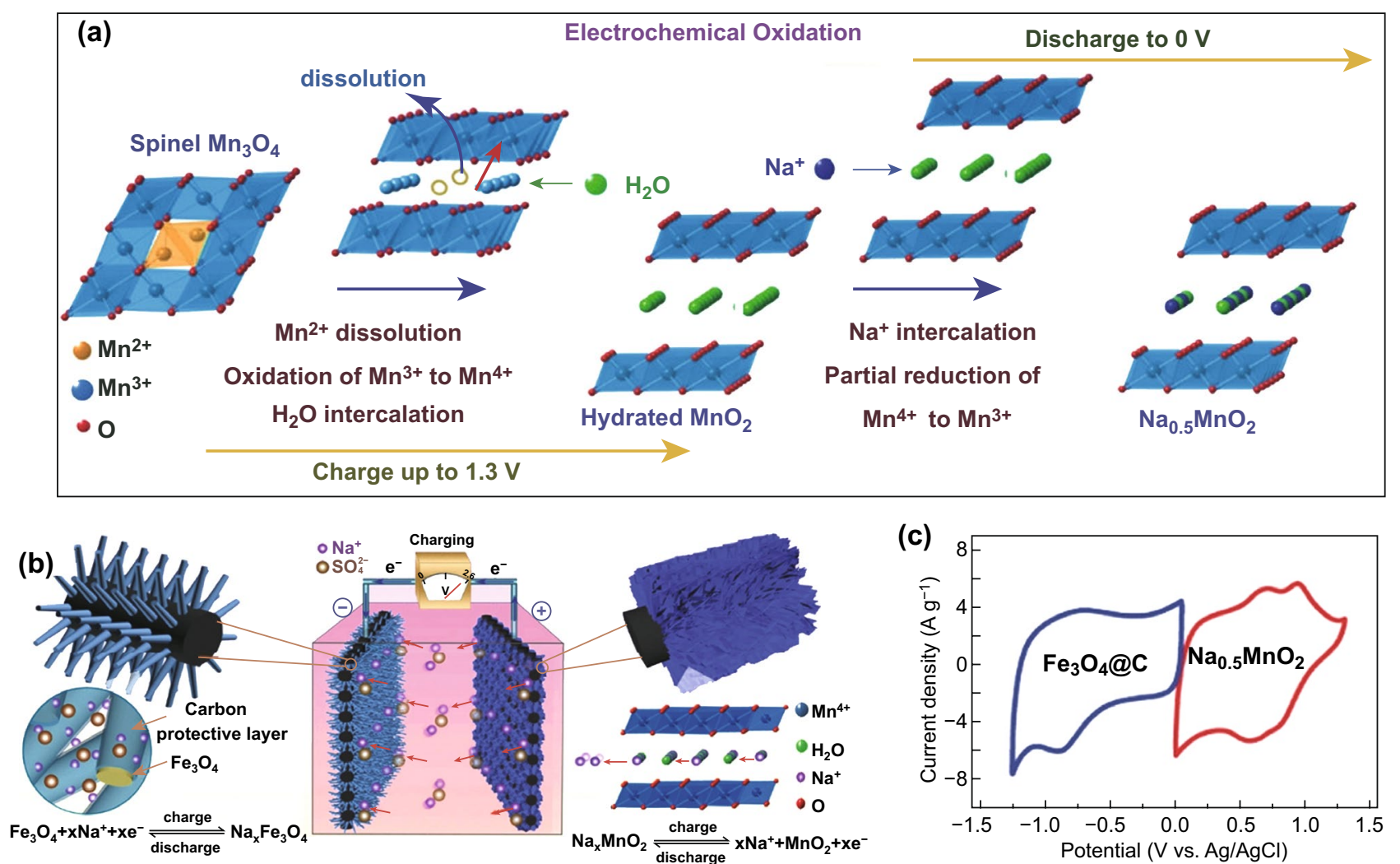

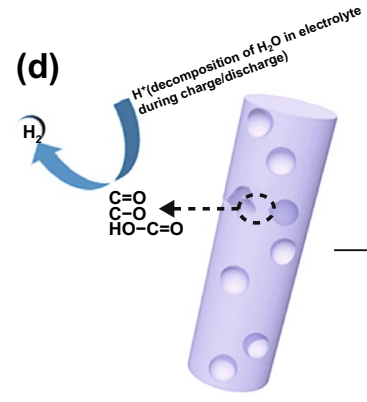

Single carbon fiber of $\mathrm{CC}$

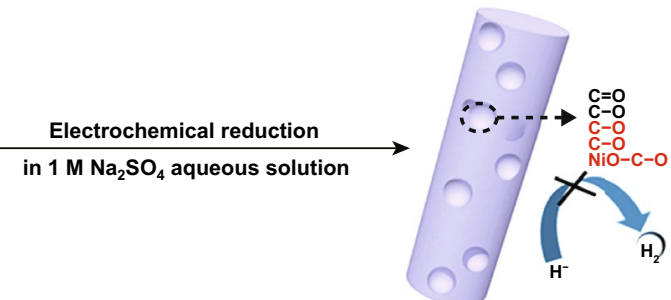

Single carbon fiber of $\mathrm{Na}-\mathrm{CC}$

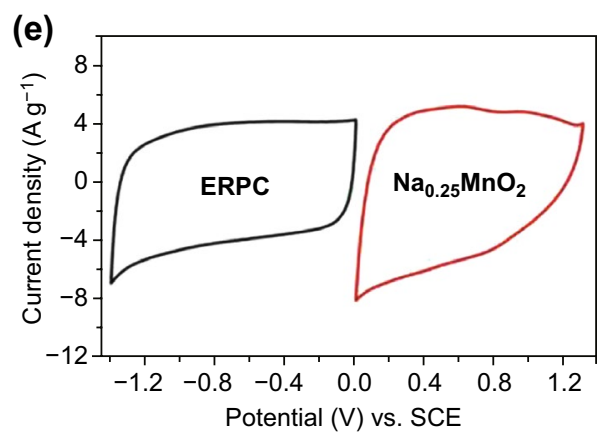

Fig. 2 a Structural evolution process of $\mathrm{Na}_{0.5} \mathrm{MnO}_{2}$ during the electrochemical oxidation. b Electrode designs and charge-storage mechanism of the $\mathrm{Fe}_{3} \mathrm{O}_{4} @ \mathrm{C}$ anode and the $\mathrm{Na}_{0.5} \mathrm{MnO}_{2}$ NWAs cathode in the aqueous ASC system. c CV curves of the $\mathrm{Na}_{0.5} \mathrm{MnO}_{2} \mathrm{NWAs}$ and Fe $\mathrm{O}_{4} @ \mathrm{C}$ electrodes in separate potential ranges at a scan rate of $10 \mathrm{mV} \mathrm{s}^{-1}$. Adapted with permission from Ref. [31]. d Reaction schematic of alkali cations $\left(\mathrm{Na}^{+}\right)$on carbon-based electrodes. Adapted with permission from Ref. [28]. e CV curves of the $\mathrm{Na}_{0.25} \mathrm{MnO}_{2}$ and the ERPC electrodes in separate potential ranges at a scan rate of $25 \mathrm{mV} \mathrm{s}^{-1}$. Adapted with permission from Ref. [43]

the positive electrode, separately [48]. Moreover, Qin et al. also assembled a $2.1 \mathrm{~V}$ aqueous carbon-based SC which is composed of heteroatom-rich micropore carbon fiber fabric (CC) as cathode and Na-containing functional groups CC (Na-CC) as anode, respectively [28].

So far, $\mathrm{Na}^{+}$is reported as the most common alkali cation to enlarge the electrode potential range. In aqueous media, $\mathrm{Na}^{+}$will be hydrated by surrounding water molecules to form hydrated $\mathrm{Na}^{+}$particles. Due to the strong $\mathrm{Na}^{+}-\mathrm{H}_{2} \mathrm{O}$ interaction, the radius of hydrated $\mathrm{Na}^{+}$can even attain to $3.58 \AA$, resulting in the inferior mobility and conductivity. Consequently, it is necessary to search for other hydrated alkali cations with the smaller hydration radius. Among various candidates, the radius of hydrated $\mathrm{K}^{+}$is only $3.31 \AA$ and this property endows the hydrated $\mathrm{K}^{+}$possesses the superior conductivity and mobility during the charge/discharge 
process. Recently, Xiong et al. assembled a $2.4 \mathrm{~V}$ aqueous SC device comprised of $\mathrm{K}_{0.6} \mathrm{MnO}_{2}$ (positive electrode), $\mathrm{K}^{+}$-adsorbed holey carbon (negative electrode), and $1 \mathrm{M}$ KTFSI solution (electrolyte) [39]. Benefiting from the $\mathrm{K}^{+}$ modification, this $\mathrm{K}_{0.6} \mathrm{MnO}_{2} / / \mathrm{KHC}$ device could deliver a $52.8 \mathrm{Wh} \mathrm{kg}^{-1}$ at $500 \mathrm{~kW} \mathrm{~kg}^{-1}$ and $95 \%$ capacitance retention after 10,000 cycles at $20 \mathrm{Ag}^{-1}$. In addition, to further contrast the applications of doping alkali cations in the field of high-voltage aqueous SCs, these aforesaid recent works are also exhibited in Table 1.

As mentioned above, doping alkali cations into electrode materials is an effective and universal method to broaden the cell voltage of aqueous SCs. In general, this strategy can not only modify the electric double-layer capacitive electrodes, but also optimize the pseudo-capacitive electrodes. In other words, this strategy is suitable for boosting the cell voltage of aqueous symmetric SCs and ASCs. Additionally, selecting appropriate electrodes is a crucial factor for the success of this strategy. Normally, the host materials should possess porous structure which can provide abundant channels for cations intercalation and reactive sites for cations adsorption process. Besides the alkali cations listed above, more doping particles with high mobility and conductivity should be explored in the future works.

\subsection{Modulating the Electrode Mass Ratio}

Except for the electrocatalytic activity of electrodes, the unsuitable electrode potential range is another adverse factor to impede the development prospects of high-voltage aqueous SCs. As reported by the previous studies, the upper limit potential $\left(P_{\mathrm{U}}\right)$ and low limit potential $\left(P_{\mathrm{L}}\right)$ are two vital parameters to determine the maximum cell voltage of aqueous SCs $[49,50]$. Theoretically, the maximum cell voltage of aqueous SCs should be equal to the difference between $P_{\mathrm{U}}$ and $P_{\mathrm{L}}\left(P_{\mathrm{U}}-P_{\mathrm{L}}\right)$. Nevertheless, the practical cell voltage is very difficult to reach the theoretical value due to the restriction of potential of zero voltage $\left(P_{0 \mathrm{~V}}\right)$. In aqueous SC devices, $P_{0 \mathrm{~V}}$ represents the cutoff potential of both cathode and anode when the device operates at $0 \mathrm{~V}$ [49]. Generally, the potential range of negative and positive electrode refers to $P_{\mathrm{L}}$ to $P_{0 \mathrm{~V}}$ and $P_{0 \mathrm{~V}}$ to $P_{\mathrm{U}}$, respectively. Limited by the intrinsic features of electrodes, the location of $P_{0 \mathrm{~V}}$ normally deviates from the middle value of $\left(P_{\mathrm{U}}-P_{\mathrm{L}}\right)$ and thus leads to the potential range of cathode which is unequal to the anode [51]. In such a condition, one electrode will reach the limit potential $\left(P_{\mathrm{U}}\right.$ or $\left.P_{\mathrm{L}}\right)$ sooner than the other electrode and the voltage region of the latter will not be fully exploited during the charge/discharge process $[49,52]$. To address this challenge, it is worthwhile searching for efficacious measures to optimize the electrode potential range. As an attractive method, modulating the electrode mass ratio has received significant attentions in recent years and the mechanism of this strategy is displayed as Eqs. 1 and 2 [53]:

$Q=C \times m \times \Delta E$

$\frac{m_{+}}{m_{-}}=\frac{C_{-} \times \Delta E_{-}}{C_{+} \times \Delta E_{+}}$

In Eq. 1, the parameters of $Q, C, m$, and $\Delta E$ stand for the surface charge stored in each electrode, specific capacitance, active mass, and potential range, respectively. Normally, the stored charges of positive electrode should be equal to the negative electrode $\left(Q_{+}=Q_{-}\right)$. Otherwise, the as-assembled device is unable to guarantee to work reversibly during the repeated cycling process [50]. In Eq. 2, the parameters of $m_{+}$ and $m_{-}$refer to the active mass of two electrodes. Whereas $C_{-}$and $\Delta E_{-}$are the specific capacitance and potential

Table 1 The comparison of recent works about doping alkali cations in the field of high-voltage aqueous SCs

\begin{tabular}{|c|c|c|c|c|c|}
\hline Electrode materials & Electrolyte & Alkali cations & Cell voltage $(\mathrm{V})$ & $\begin{array}{l}\text { Energy density }\left(\mathrm{Wh} \mathrm{kg}^{-1}\right) / \\
\text { power density }\left(\mathrm{W} \mathrm{kg}^{-1}\right)\end{array}$ & References \\
\hline $\mathrm{Na}_{0.5} \mathrm{MnO}_{2}(+) / / \mathrm{Fe}_{3} \mathrm{O}_{4} @ \mathrm{C}(-)$ & $1 \mathrm{M} \mathrm{Na}_{2} \mathrm{SO}_{4}$ & $\mathrm{Na}^{+}$ & 2.6 & $81 / 647$ & {$[31]$} \\
\hline $\mathrm{Na}_{0.25} \mathrm{MnO}_{2}(+) / / \operatorname{ERPC}(-)$ & $1 \mathrm{M} \mathrm{Na}_{2} \mathrm{SO}_{4}$ & $\mathrm{Na}^{+}$ & 2.7 & $61.1 / 982$ & {$[43]$} \\
\hline $\mathrm{C} @ \mathrm{Mn}_{3} \mathrm{O}_{4}(+) / / \mathrm{Na}-\mathrm{FG}-\mathrm{CC}(-)$ & $1 \mathrm{M} \mathrm{Na}_{2} \mathrm{SO}_{4}$ & $\mathrm{Na}^{+}$ & 2.7 & $110.4 / 1352$ & {$[48]$} \\
\hline $\mathrm{CC}(+) / / \mathrm{Na}-\mathrm{CC}(-)$ & $1 \mathrm{M} \mathrm{Na}_{2} \mathrm{SO}_{4}$ & $\mathrm{Na}^{+}$ & 2.1 & - & {$[28]$} \\
\hline $\mathrm{K}_{0.6} \mathrm{MnO}_{2}(+) / / \mathrm{KHC}(-)$ & 1 M KTFSI & $\mathrm{K}^{+}$ & 2.4 & $52.8 / 500$ & [39] \\
\hline
\end{tabular}


window of anode, $C_{+}$and $\Delta E_{+}$represent the specific capacitance and potential window of cathode. According to the two equations, we can conclude that the electrode mass ratio is a vital factor for determining the electrode potential range (Fig. 3a). To acquire the high-voltage aqueous SCs, one of the promising strategies is to modulate the electrode mass ratios [30, 54].

For example, Calvo et al. designed aqueous ASCs consisted of carbon xerogel electrodes with various mass ratios. Based on the experimental results, this assembled device could yield a maximum cell voltage of $1.8 \mathrm{~V}$ when the optimum electrode mass ratio was close to around 2 (Fig. 3b) [55]. Similarly, Demarconnay et al. assembled a highvoltage $\mathrm{MnO}_{2} / /$ activated carbon (AC) aqueous ASC device through optimizing the electrode mass ratio [19]. When an integrated system was composed of both electrodes with the optimal mass ratio (2.5), the maximum cell voltage of this device could attain to $2 \mathrm{~V}$ (Fig. 3c, d). Besides, Wang et al. also utilized this strategy to explore the relationship between the electrode mass ratio and the cell voltage of aqueous SCs consisted of polyaniline (PANI) and $\mathrm{RuO}_{2}$ [56]. For the $\mathrm{PANI} / / \mathrm{PANI}$ and $\mathrm{RuO}_{2} / / \mathrm{RuO}_{2}$ systems, these devices could achieve the maximum cell voltage when the electrodes mass ratio was on the verge of around 1 , whereas the $\mathrm{RuO}_{2} / / \mathrm{PANI}$ device with an electrode mass ratio of 0.81 will yield the maximum cell voltage in comparison with the SC system with an electrode mass ratio of 0.26 and 1.09 .

In summary, modulating the electrode mass ratio is a satisfactory approach possessing the advantages of simple operation and low cost to enlarge the cell voltage of aqueous SCs, which seems to be suitable for large-scale industrial applications. According to Eqs. 1 and 2, it is convenient to calculate the theoretical optimal electrode mass ratio. After the precise adjustment, the utilization rate of electrode potential range could be significantly expanded. Nevertheless, this strategy cannot adjust the location of $P_{0 \mathrm{v}}$, leading to the improvement


Fig. 3 a Mechanism illustration showing the strategy to increase the cell voltage of aqueous SCs through modulating the electrode mass ratio. b Function relationship between coulombic efficiency and operating voltage for the carbon xerogel-based asymmetric systems with different electrode mass ratios. Adapted with permission from Ref. [55]. c CV curves of $\mathrm{MnO}_{2} / / \mathrm{AC}$ device operating in $0.5 \mathrm{M} \mathrm{Na}_{2} \mathrm{SO}_{4}$ with mass ratios of 2.5 at scan rate of $2 \mathrm{mV} \mathrm{s}^{-1}$. d Galvanostatic charge/discharge curves of $\mathrm{MnO}_{2} / / \mathrm{AC}$ device for mass ratio of 2.5. Adapted with permission from Ref. [19] 
of energy density is insufficient. In addition, due to the lack of scientific analysis methods, it is complicated and timeconsuming to acquire the practical optimal electrode mass ratio through numerous experimental gradient designs.

\subsection{Optimizing the Surface Charge Density}

In addition to the electrode mass ratio, the surface charge density is another pivotal factor to affect the electrode potential range [51]. Hence, it is feasible to enlarge the electrode potential range through optimizing the surface charge density. Compared with modulating the electrode mass ratio, this strategy is convenient and high efficiency to gain the appropriate electrodes. Besides, it can simultaneously increase the potential range and capacitance of electrodes through adjusting the location of $P_{0 \mathrm{~V}}$ (Fig. 4a).

According to the previous reports, electrochemical charge injection (ECI) technique is normally applied to induce the variations of charge density via changing the initial potential of electrodes [26, 57]. Based on the various reaction mechanisms, ECI technique is mainly divided into two generic methods: Faradaic and non-Faradaic charge injection. In Faradic charge inject, it employs the Faradic reactions with counter ions to induce the variations of electrode charge density in electrolytes. While, the non-Faradic charge injection relies on the double-layer adsorption of counter ions to alter the charge density [51]. Due to its high reversibility, the non-Faradic charge injection is more suitable for the most energy storage devices. On this basis, the applications of

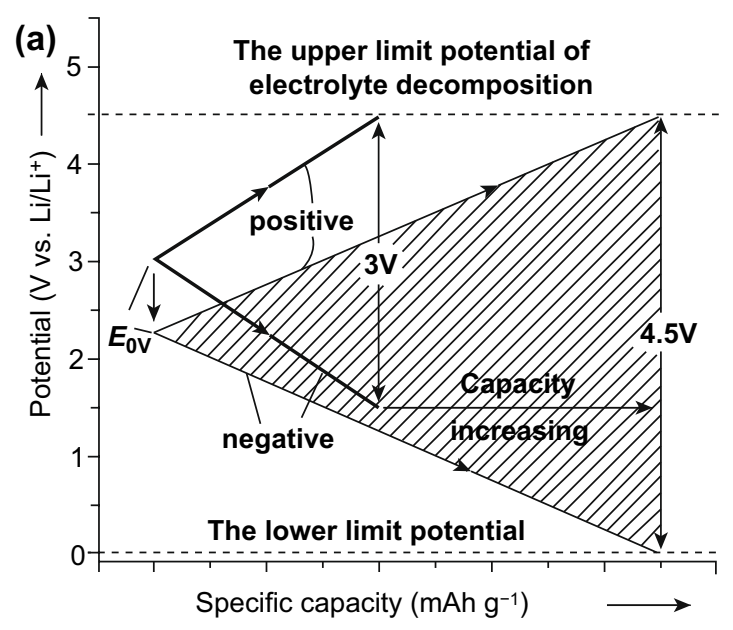

(c)



(b)


Multi-scaled porous carbon
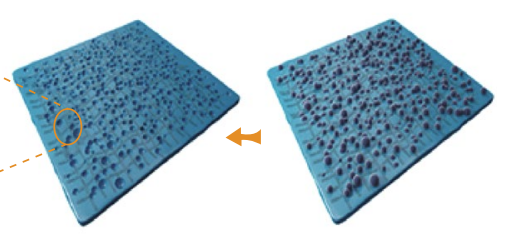

Washing with $\mathrm{H}_{2} \mathrm{SO}_{4}$
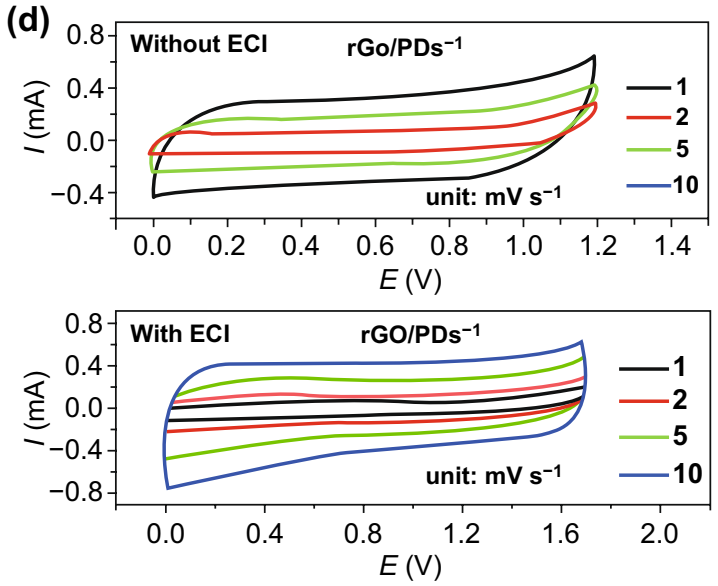

Fig. 4 a Mechanism illustration of optimizing the surface charge density to extend the electrode potential window. The shadowed area is equal to the value of the energy density. Adapted with permission from Ref. [51]. The illustration of $\mathbf{b}$ the synthesis procedure of MSPC on carbon cloth and $\mathbf{c}$ tuning the electrode potential range downward through pre-charging treatment. Adapted with permission from Ref. [59]. $\mathbf{d}$ CV curves of rGO/PDs-1-based FSC without (above) and with ECI (below). Adapted with permission from Ref. [60] 
ECI technique have received substantial attentions in recent years. For instance, the ECI technique was applied for a $\mathrm{V}_{2} \mathrm{O}_{5} / / \mathrm{AC}$ device operating in $2 \mathrm{M} \mathrm{LiNO}_{3}$ electrolyte [58]. When the initial potential of both electrodes was adjusted to $0.2 \mathrm{~V}$ (vs. SCE), this device could afford a maximum cell voltage of $1.8 \mathrm{~V}$.

Similarly, this technique also holds great promise to extend the cell voltage of aqueous symmetric SCs. Recently, Yu et al. applied the ECI technique to boost the cell voltage of a multi-scale porous carbon (MSPC)-based aqueous symmetric SC [59]. Through elaborately selecting the precharging potential and tuning the $P_{0 \mathrm{~V}}$ downward, the maximum cell voltage was significantly expanded from 1.4 to $1.8 \mathrm{~V}$ (Fig. 4b, c). Subsequently, Guo et al. also widened the cell voltage of reduced graphene oxide/polymer dots ( $\mathrm{rGO} /$ PDs)-based flexible symmetric SC (FSC) via the ECI technique [60]. After the adjustment of surface charge density, this built device could produce a maximum cell voltage of $1.7 \mathrm{~V}$, much higher than that of $1.2 \mathrm{~V}$ for FSC without CEI treatment (Fig. 4d).

From the examples above, it is a rational and high-efficiency strategy to expand the cell voltage of aqueous SCs via optimizing the surface charge density. As an available method, ECI technique can validly tune the surface charge density through adjusting the position of $P_{0 \mathrm{~V}}$. However, this strategy cannot accurately control the degree of precharging treatment due to the self-discharge behavior which may reduce the energy utilization efficiency of aqueous SCs $[49,59]$. Hence, how to mitigate the adverse impact of selfdischarge phenomenon is the pivotal challenge for this strategy. Moreover, apart from CEI technique, more effective techniques should be explored to optimize the surface charge density, such as applying thermo-electrochemical effects and introducing different functional groups [26, 44, 61].

\section{Optimizing the Electrolyte Properties}

Besides electrode materials, electrolyte is another pivotal component for aqueous SCs [53]. Due to the restriction of undesirable water electrolysis, aqueous electrolyte normally generates a narrow ESW and thus hampers the application prospect of aqueous SCs. As for this bottleneck, adjusting an appropriate $\mathrm{pH}$ level, introducing redox mediators, and constructing "water-in-salt" electrolyte are regarded as three popular and efficient pathways to boost the cell voltage of aqueous SCs in recent years [62-64]. In view of this, the relevant mechanisms and research advances of these approaches will be introduced in the subsequent sections.

\subsection{Adjusting the Appropriate pH Level}

Generally, the PH level in electrolyte represents the concentration of $\mathrm{H}^{+}$and $\mathrm{OH}^{-}$. Aqueous electrolytes can be mainly classified into acidic (e.g., $\mathrm{H}_{2} \mathrm{SO}_{4}$ ), alkaline (e.g., $\mathrm{KOH}$ ), and neutral (e.g., $\mathrm{Na}_{2} \mathrm{SO}_{4}$ ) based on their $\mathrm{pH}$ value [7, 53]. More recently, researchers have found that some electrochemical reactions in aqueous media are greatly affected by the $\mathrm{pH}$ level of electrolyte, such as faradic redox reactions and water electrolysis process (e.g., HER and OER) [26]. To investigate the relationship between electrochemical reactions and electrolyte $\mathrm{pH}$ levels, two half reactions of water decomposition in neutral medium and corresponding Nernst equations are displayed as Eqs. 3 and 4 [65]:

$[+] 2 \mathrm{H}_{2} \mathrm{O} \Leftrightarrow \mathrm{O}_{2}+4 \mathrm{e}^{-}+4 \mathrm{H}^{+} \quad \mathrm{E}_{\mathrm{ox}}=1.23-0.059 \mathrm{pH}$

$[-] \quad \mathrm{H}_{2} \mathrm{O}+2 \mathrm{e}^{-} \Leftrightarrow \mathrm{H}_{2}+2 \mathrm{OH}-\mathrm{E}_{\text {red }}=-0.059 \mathrm{pH}$

In view of Eqs. 3 and 4, it can be deduced that $\mathrm{pH}$ level is strongly correlated with the water electrolysis activity. According to the Pourbaix diagram, the maximum ESW of aqueous electrolyte will be obtained when the oxidation reaction occurs in an acidic environment (low $\mathrm{pH}$ value), and the reduction reaction takes place in an alkaline condition (high $\mathrm{pH}$ value) $[65,66]$.

As mentioned before, adjusting an appropriate $\mathrm{pH}$ level of electrolyte is beneficial for improving the cell voltage of aqueous SCs. For instance, Khomenko et al. established a $\mathrm{MnO}_{2} / / \mathrm{AC}$ device operating in various $\mathrm{pH}$ values electrolytes to verify the relationship between the over-potential of HER/OER and the $\mathrm{pH}$ values of electrolyte [67]. According to the experimental results, the system would deliver a maximum cell voltage of $2 \mathrm{~V}$ when the electrolyte was $2 \mathrm{M} \mathrm{KNO}_{3}$ ( $\mathrm{pH}=6.4$ ). Moreover, Zhao et al. contrasted the potential window of the as-prepared $\mathrm{NiCo}_{2} \mathrm{O}_{4} / \mathrm{CC}$ electrode in $\mathrm{KOH}$ alkaline electrolyte and mixed $\mathrm{LiSO}_{4} / \mathrm{CoSO}_{4}$ neutral electrolyte, respectively (Fig. 5a) [68]. In a three-electrode system, the potential range of $\mathrm{NiCo}_{2} \mathrm{O}_{4} / \mathrm{CC}$ electrode in mixed neutral electrolyte could be enlarged to $0-1.2 \mathrm{~V}$ (vs. SCE), which is superior to that measured in alkaline electrolyte $(0-0.5$ V) (Fig. 5b, c). 

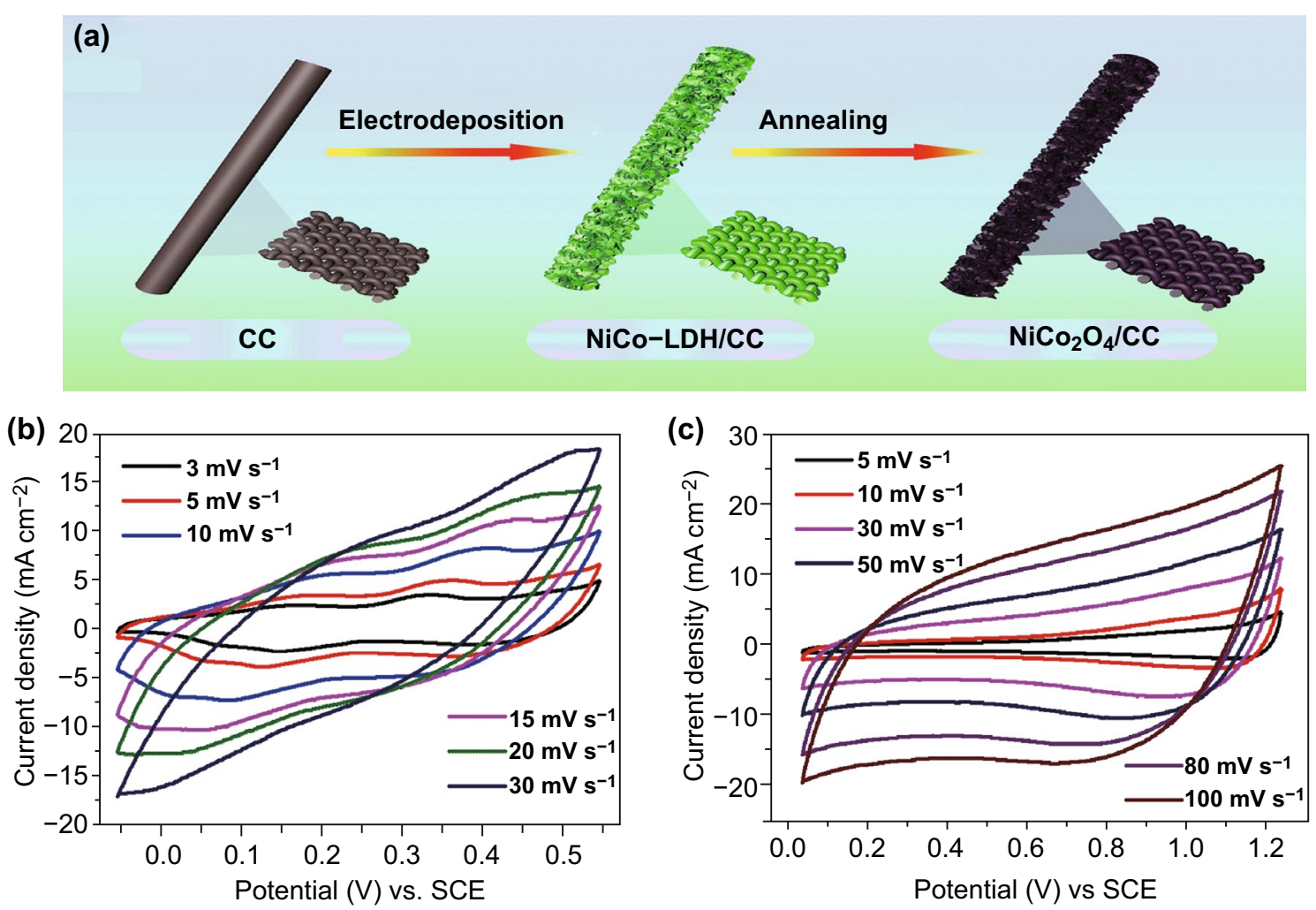

Fig. 5 a Schematic illustration of the fabrication process of the $\mathrm{NiCo}_{2} \mathrm{O}_{4} / \mathrm{CC}$ composite. The $\mathrm{CV}$ profiles of the as-fabricated $\mathrm{NiCo} \mathrm{O}_{4} / \mathrm{CC}$ electrode at a three-electrode system $\mathbf{b}$ in alkaline electrolyte and $\mathbf{c}$ in neutral electrolyte with different scan rates. Adapted with permission from Ref. [68]

It is evident that these aforesaid cases merely verify that the $\mathrm{pH}$ level of electrolyte is greatly correlated with the cell voltage and ignore to take efficacious measures to adjust the $\mathrm{pH}$ value of electrolytes. In view of this, Slesinski et al. proposed a novel intrinsic $\mathrm{pH}$ gradient strategy to extend the cell voltage of neutral aqueous $\mathrm{SCs}$ (pH of both electrode/ electrolyte interfaces differs by six units) [65]. Considering their superior donor-acceptor characters, the optimized carbon materials were applied as electrode materials. Through a modification with ammonia, the self-controlled $\mathrm{pH}$ gradient was introduced into this $\mathrm{SC}$ device and formed a protective layer on the electrode surface. In aqueous media, ammonia molecules not only increase the local $\mathrm{pH}$, but also serve as protectors against electrode oxidation or electrolyte decomposition, thereby enlarging the ESW of aqueous electrolyte. Benefiting from this novel design, the as-synthesized aqueous SC system could exhibit a maximum cell voltage of $1.8 \mathrm{~V}$. In addition, it is feasible to adjust the $\mathrm{pH}$ level of electrolytes via constructing the unique SC device. Recently, Wang et al. introduced a bipolar assembly of ion-exchange membranes (IEMs) as the separator for aqueous SC, which enabled cathode and anode to work in acidic and alkaline electrolyte, respectively [69]. Since the HER and OER process was blocked by the migration of $\mathrm{H}^{+}$and $\mathrm{OH}^{-}$confined in the acidic and alkaline electrolyte chambers, this built carbon-based SC device with dual aqueous electrolytes could deliver a wide cell voltage of around $1.8 \mathrm{~V}$.

In conclusion, the ESW of aqueous media is greatly correlated with its $\mathrm{pH}$ value. Generally, the cell voltage of aqueous SCs with neutral electrolyte is wider than that of acidic/alkaline electrolyte owing to the low HER/OER activity. Hence, engineering an applicable electrolyte $\mathrm{pH}$ level is regarded as an effective approach to construct the high-voltage aqueous SCs. However, the above-mentioned modification measures are unable to fulfill the demands of industrial manufacture due to the complicated procedures and expensive price. As a result, it is urgent to search for more convenient and practical methods to adjust the appropriate $\mathrm{pH}$ value of electrolytes. 


\subsection{Introducing Redox Mediators}

Benefiting from the vast development prospect, constructing redox electrolyte has received various attentions to promote the performance of aqueous SCs in the past years (Fig. 6a) $[64,70,71]$. According to the various reaction mechanisms, redox electrolytes are mainly classified into redoxadditives electrolytes (redox mediators are added into aqueous media to improve the electron-transfer kinetics on the electrode-electrolyte interface) and redox-active electrolytes (redox mediators are directly applied as aqueous electrolytes to undergo fast electron transfer reactions) [72, 73]. It should be pointed that redox mediator is the key component of redox electrolytes. Normally, redox mediators are divided into inorganic and organic redox mediators, respectively. The inorganic mediators (e.g., transition metal ions, halide ions, and cyanide ions) are the common redox additives for aqueous electrolyte, offering pseudo-capacitance via chemical valence variation, while the organic redox mediators (e.g., methylene blue, indigo carmine, and $p$-phenylenediamine) can achieve capacitance improvement via the conjugated effect [26, 64, 74]. Moreover, redox mediators can also be grouped into single and dual redox mediator based on the diverse species. When redox mediators are dissolved in aqueous solvent, the dissociative cations or anions will be adsorbed on the electrode surface through either electrostatic or physical behaviors and induce the extra redox reactions to increase the charge storage capacity [29, 75]. Consequently, the assembled aqueous SC operating in the redox electrolyte will substantially increase the energy density without sacrificing the power density (Fig. 6b) [75].
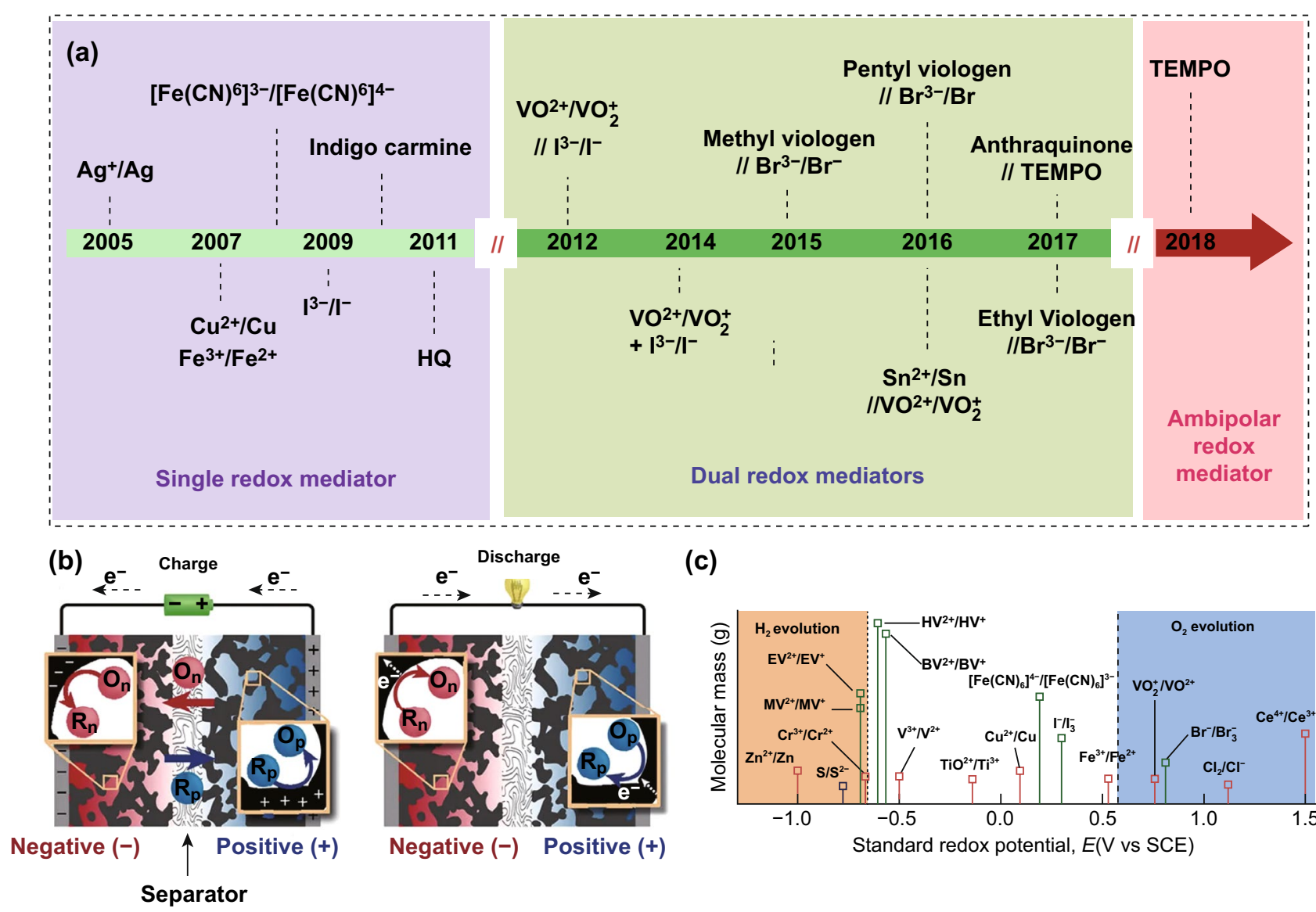

(c)



Fig. 6 a Timeline of the development of redox couples in the field of SCs. HQ and TEMPO refer to hydroquinone and 2,2,6,6-tetramethylpiperidinyloxyl. Adapted with permission from Ref. [64]. b Schematic showing capacitive and faradic charge-storage processes of redox couples in electrolyte. c Reduction potentials of the couples considered relative to the thermodynamic stability window of water at neutral $\mathrm{pH}$ (white region). The lines colored in red, green, and blue are for couple stable in acidic, neutral, and basic conditions, respectively. BV: benzyl viologen, EV: benzyl viologen, HV: heptyl viologen, MV: methyl viologen, SCE: standard calomel electrode. Adapted from with permission Ref. [76]. (Color figure online) 
Besides the improvement of capacitance, this strategy is also suitable for increasing the cell voltage of aqueous SCs. It is well known that every redox mediator possesses a certain redox potential (Fig. 6c). During the charging process, the redox electrolyte will be oxidized (cathode) and reduced (anode) at the electrode surface, respectively. However, the variation of redox electrolyte is contrary during the discharge process. Along with the redox reaction, every redox mediator will exhibit an individual redox potential. If we select an appropriate redox mediator with redox potential near the $\mathrm{H}_{2} \mathrm{O}$ decomposition window, the cell voltage will be effectively boosted. This fact is attributed to the kinetic of redox mediator that is faster than water electrolysis, thus reducing the activity of water electrolysis $[26,76]$.

More recently, boosting the cell voltage of aqueous SCs via introducing redox mediators has aroused considerable attentions from researchers. As an example, Li et al. established a high-voltage aqueous SCs with a potassium bromide $(\mathrm{KBr})$ electrolyte [77]. Owing to the high redox potential of $\mathrm{Br}^{-} / \mathrm{Br}_{3}^{-}$in neutral aqueous media, this built system was capable of delivering a high cell voltage of $1.9 \mathrm{~V}$. Moreover, Hwang et al. fabricated a $2.0 \mathrm{~V}$ activated carbon-based aqueous ASC device with redox electrolyte [78]. Such an admirable cell voltage is ascribed to the fast redox kinetics of $\left[\mathrm{Fe}(\mathrm{CN})_{6}\right]^{4-} /\left[\mathrm{Fe}(\mathrm{CN})_{6}\right]^{3-}$ and the unique design of porous-structure electrodes (Fig. 7a, b). Similarly, Sundriyal et al. assembled a $1.8 \mathrm{~V} \mathrm{rGO} / \mathrm{TiO}_{2} / / \mathrm{rGO} / \mathrm{TiO}_{2}$ device with a redox additive electrolyte (i.e., $0.2 \mathrm{M} \mathrm{K}_{3}\left[\mathrm{Fe}(\mathrm{CN})_{6}\right]$ in $1 \mathrm{M}$ $\mathrm{Na}_{2} \mathrm{SO}_{4}$ ) [79]. It is notable that all of these examples merely added single redox mediator into aqueous electrolyte. In fact, this strategy cannot simultaneously optimize the performance of both electrodes due to the asymmetric properties of cathode and anode. For example, it was reported that the positive electrode exhibited a battery-type behavior and negative electrode displayed a pure capacitive behavior when adding hydroquinone into $1 \mathrm{M} \mathrm{H}_{2} \mathrm{SO}_{4}$ electrolyte, resulting in a big discrepancy of charge/discharge behavior of both electrodes [80]. Notably, the same phenomenon was also observed when applying other redox mediators, such as $\mathrm{K}_{4}\left[\mathrm{Fe}(\mathrm{CN})_{6}\right]$, KI, and methylene blue [81-83].

In light of this, constructing a dual redox mediator electrolyte is regarded as a satisfactory strategy to remedy the above short slab. In general, dual redox mediator electrolyte is composed of two redox mediators with different redox potentials. One mediator with lower potential is applied for the negative electrode, whereas the other one with higher potential operates at the positive electrode [64]. Based on this configuration, two individual redox mediators can maximally expand the potential range of redox reactions on the two electrode surfaces, thus improving the cell voltage of intact aqueous SCs. Considering these advantages, the relevant studies of dual redox mediator electrolytes have gained substantial interests in the past years. Recently, Sun et al. exhibited a 2D carbon-based aqueous SC with dual redox mediator electrolyte [84]. Through introducing KI and anthraquinone-2-sulfonic acid sodium (AQS) into neutral $\mathrm{KNO}_{3}$ solution, this device with dual redox mediator electrolyte delivered a maximum cell voltage of $1.8 \mathrm{~V}$ and a high energy density of $33.81 \mathrm{Wh} \mathrm{kg}^{-1}$. Subsequently, Tian et al. constructed a high energy density modified activated carbon felt-based (ACF) aqueous SC with asymmetric redox additive electrolytes by adding $\mathrm{K}_{3}\left[\mathrm{Fe}(\mathrm{CN})_{6}\right]$ and 2,6-dihydroxyanthraquinone (2,6-DHAQ) in $2 \mathrm{M} \mathrm{KOH}$ as positive and negative redox electrolytes, respectively [70]. Profiting from the enhancement of fast and reversible faradic reactions, this device was able to display a maximum cell voltage of $2 \mathrm{~V}$ and a high energy density of $39.1 \mathrm{Wh} \mathrm{kg}^{-1}$ (Fig. 7c, d).

From the foregoing, it is a favorable and efficacious avenue to increase the cell voltage of aqueous SCs through introducing redox mediator. The main advantages of this strategy are simple, cost-effective, and safe fabrication process in comparison with other methods. Furthermore, it can simultaneously enhance the capacitance and cell voltage of aqueous SCs, thereby maximizing the energy density. However, the self-discharge behavior is a main bottleneck to restrict the applications of this approach. Generally, the self-discharge phenomenon is caused by cross-diffusion and redox shuttling of charged redox couples between the oppositely polarized electrodes in the cell (Fig. 7e). This behavior may result in the low coulombic efficiency and irreversible side reactions [74]. As a consequence, it is desirable to investigate the innovative self-discharging suppression mechanisms. Besides, the number of reported redox mediators is still rare. Hence, it is a long way to find more proper redox mediators.

\subsection{Constructing "Water-in-Salt" Electrolyte}

It is well known that increasing the concentration of electrolyte salt is also a satisfactory and smart pathway to enlarge the cell voltage of aqueous SCs in recent years $[85,86]$. 
(a)

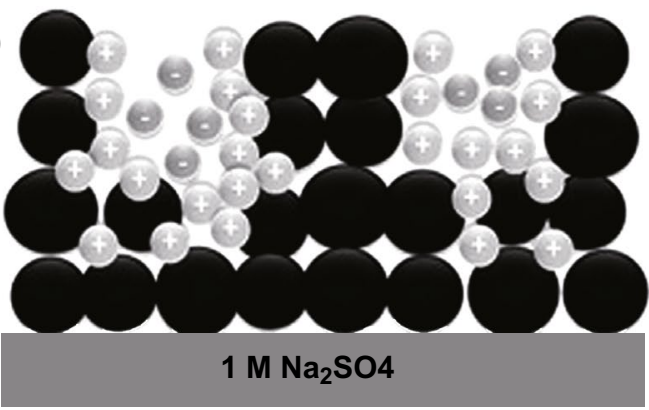

(b) 60

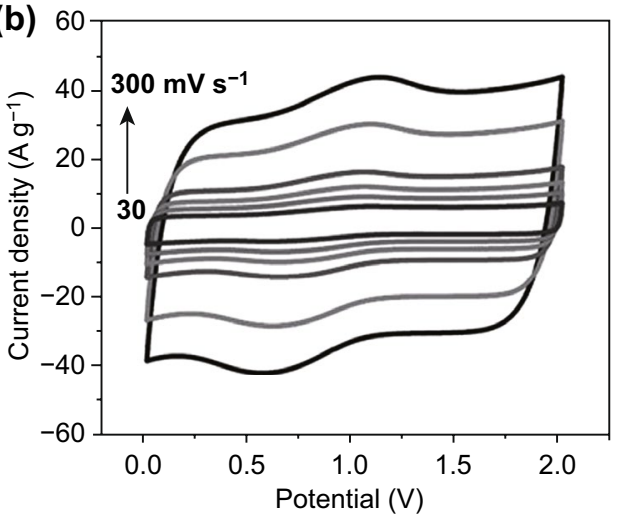

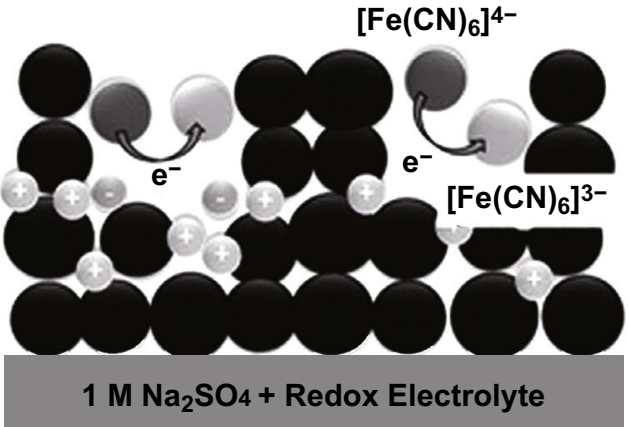

(c)

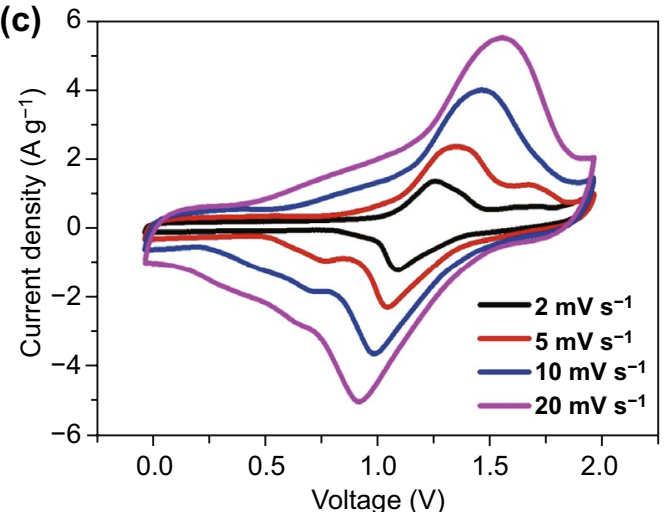

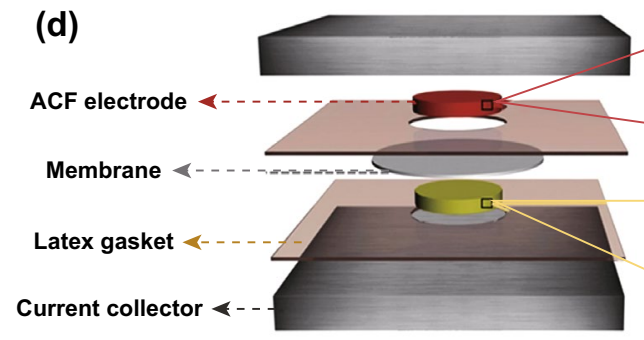

Redox reactions in negative electrode:

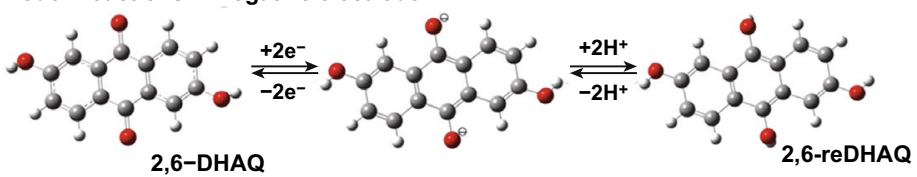

Redox reactions in positive electrode:

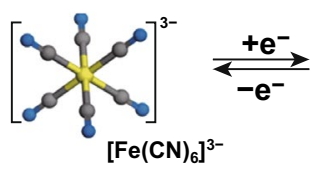
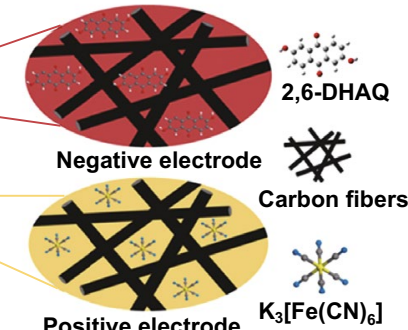

Positive electrode $\mathrm{K}_{3}\left[\mathrm{Fe}(\mathrm{CN})_{6}\right]$ (e)
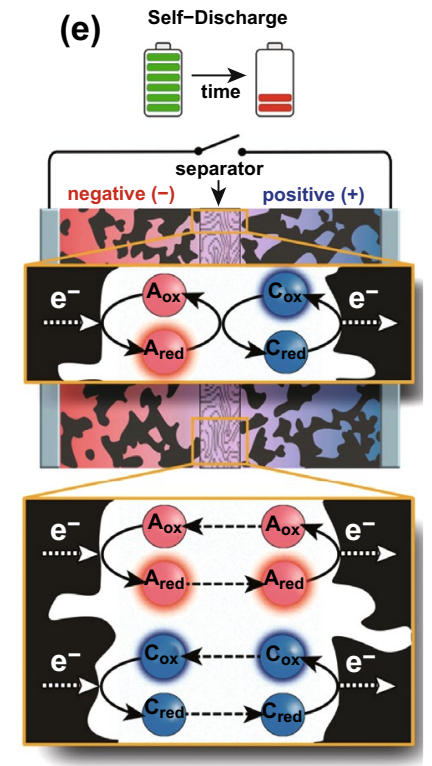

Fig. 7 a Illustration of the charge storage mechanism in an carbon-based electrode using a $1.0 \mathrm{M} \mathrm{Na}_{2} \mathrm{SO}_{4}$ electrolyte (left) in the absence and (right) in the presence of a redox mediator. b CV curves of as-prepared carbon-based aqueous SC with different scan rates. Adapted with permission from Ref. [78]. c CV curves of carbon-based aqueous SC with various scan rates. $\mathbf{d}$ Schematic of the carbon-based SC with asymmetric redox additive electrolytes and corresponding redox reactions. Adapted with permission from Ref. [70]. e Schematic illustration of the selfdischarge mechanism. Adapted with permission from Ref. [74]

In aqueous media, high concentration electrolyte salt can effectively improve the reversibility of electrochemical reactions, enhance the stability of water and reduce the yield of volatile side reaction products (e.g., $\mathrm{CO}, \mathrm{CO}_{2}$, and $\mathrm{H}_{2}$ ) [87, 88]. As a typical example, "water-in-salt" (WIS) electrolyte refers to an extremely high concentration, near-saturated 
electrolyte, and the amount of dissociative water molecules is much lower than solute molecules [89, 90]. In 2015, Wang et al. firstly reported the definition of WIS electrolyte and applied this electrolyte to enlarge the cell voltage of aqueous lithium-ion batteries [91]. Thanks to the high solubility in water and high stability against water electrolysis, lithium bis(trifluoromethane sulfonyl)imide (LiTFSI) is selected as electrolyte salt [92]. During experimental process, 21 molality (m) LiTFSI was dissolved in $1 \mathrm{~kg}$ water to form the WIS electrolyte. In aqueous media, LiTFSI particles will be ionized into $\mathrm{Li}^{+}$and $\mathrm{TFSI}^{-}$, respectively. With increase in salt concentration, the $\mathrm{TFSI}^{-}$conduction band minimum and the water valence band maximum will shift to lower potentials. When the concentration of electrolyte salt attains to $21 \mathrm{~m}$, this trend would lead to the decomposition of $\mathrm{TFSI}^{-}$occurs preferentially on the negative electrode before HER occurs
[93]. In such a super-concentrated electrolyte, almost all water molecules strongly coordinate to $\mathrm{Li}^{+}$, thereby suppressing the water electrolysis activity near the two electrodes (Fig. 8a) [62, 91]. On this basis, the as-synthesized highly concentrated WIS electrolyte was capable of providing a high ESW of $3.0 \mathrm{~V}$ and the assembled full aqueous lithium-ion battery configuration $\left(\mathrm{LiMn}_{2} \mathrm{O}_{4}\right.$ and $\mathrm{Mo}_{6} \mathrm{O}_{8}$ as electrodes, respectively) demonstrated a high cell voltage of $2.3 \mathrm{~V}$.

Motivated by this research, many researchers gradually pay more attention to investigating the applications of LiTFSI-based WIS electrolyte in the area of aqueous SCs [85, 94, 95]. For instance, Gambou-Bosca et al. contrasted the SC performance of $\mathrm{MnO}_{2}$-based electrode in the saltin-water ( $\mathrm{SIW}, 0.65 \mathrm{M} \mathrm{K}_{2} \mathrm{SO}_{4}, 5 \mathrm{LiNO}_{3}, 0.5 \mathrm{M} \mathrm{LiNO}_{3}$, and $\left.0.5 \mathrm{M} \mathrm{Ca}\left(\mathrm{NO}_{3}\right)_{2}\right)$ and water-in-salt (WIS, $5 \mathrm{M} \mathrm{LiTFSI}$ ) (a)

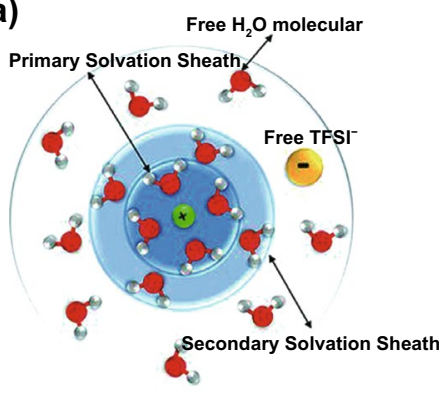

$\left\{\left[\mathrm{Li}\left(\mathrm{H}_{2} \mathrm{O}\right)_{4}\right]\left(\mathrm{H}_{2} \mathrm{O}\right)_{4}\right\}+\mathrm{nH}_{2} \mathrm{O} \mathrm{n} \geq 1$ Salt-in-Water

(c)


(b)
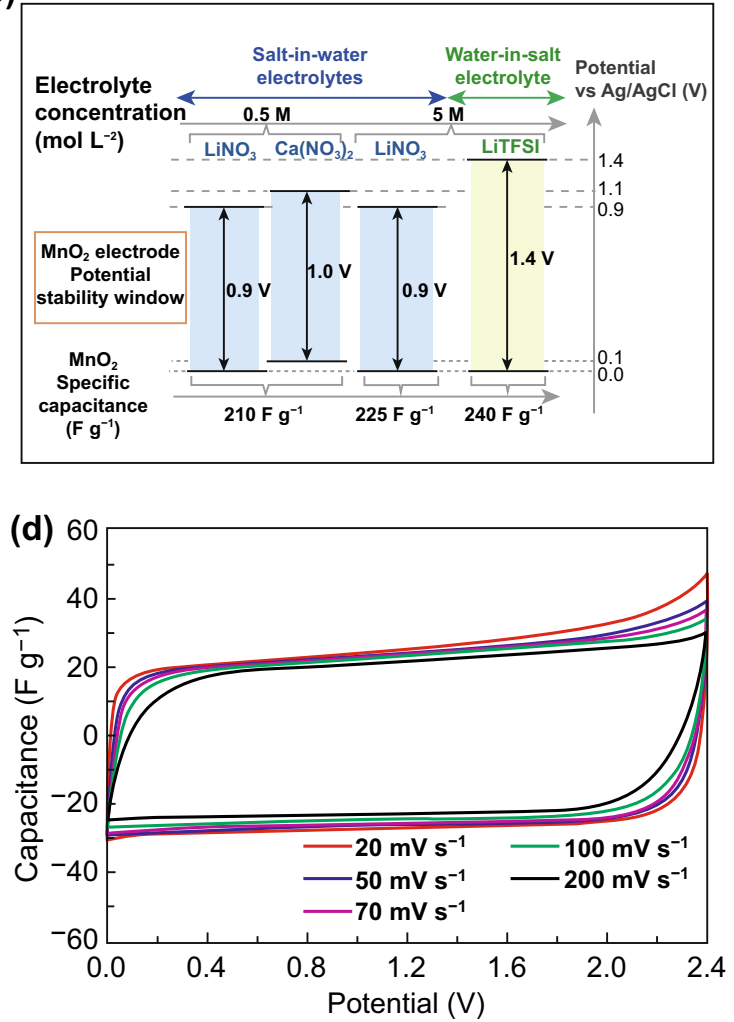

Fig. 8 a Illustration of the evolution of the $\mathrm{Li}^{+}$primary solvation sheath in diluted and water-in-salt solutions. Adapted with permission from Ref. [91]. b Potential range of $\mathrm{MnO}_{2}$ composite electrode in WIS and SIW electrolytes. Adapted with permission from Ref. [95]. c ESWs of $\mathrm{LiTFSI} / \mathrm{H}_{2} \mathrm{O} /(\mathrm{ACN})_{x}$ hybrid electrolytes. d CV curves of the SC device using YP-50F electrodes and LiTFSI/ $\mathrm{H}_{2} \mathrm{O} /(\mathrm{ACN})_{3.5}$ electrolyte at different scan rates. Adapted with permission from Ref. [94] 
electrolytes, separately [95]. According to the experimental results, it was demonstrated that the $\mathrm{MnO}_{2}$ electrode displayed an extended potential range of $1.4 \mathrm{~V}$ (vs. SCE) and admirable specific capacitance in the WIS electrolyte which is superior to the $\mathrm{MnO}_{2}$ electrode operates with the SIW electrolyte (Fig. 8b). Subsequently, Zhang et al. engineered a 2.2 V hybrid aqueous ASC device which was composed of $\mathrm{MnO}_{2}$ (positive electrode), $\mathrm{Fe}_{2} \mathrm{O}_{3}$ (negative electrode), and $21 \mathrm{~m}$ LiTFSI (electrolyte) [21]. Similarly, a $2.2 \mathrm{~V}$ polyaniline-derived carbon nanorods (PDCN)-based EDLC device was also achieved by applying $21 \mathrm{~m}$ LiTFSI as the WIS electrolyte [24].

In spite of these great achievements, there are still two major obstacles to hinder the further development of the WIS electrolyte. One challenge is the intrinsic features of WIS electrolyte. Owing to the restriction of low conductivity and high viscosity, the WIS electrolytes with high concentration are always suffering from the under-utilization of electrode materials, resulting in the poor rate performance [62]. Aiming at this phenomenon, a co-solvent-in-salt system was reported by mixing acetonitrile with the traditional WIS electrolyte $\left(21 \mathrm{~m} \mathrm{LiTFSI} / \mathrm{H}_{2} \mathrm{O}\right)$ to construct a novel "acetonitrile/water in salt" (AWIS) electrolyte [96]. According to the density functional theory-based molecular dynamics (DFTMD) simulations, it was indicated that acetonitrile molecules could easily coordinate to lithium-ions for the remaining space of the $\mathrm{Li}^{+}$solvation sheath owing to their smaller size and thus less steric interaction than $\mathrm{TFSI}^{-}$anions. Hence, this AWIS electrolyte possesses an optimal concentration of $5 \mathrm{~m}$, enhanced conductivity, lowered viscosity, and freezing temperature in comparison with the conventional WIS electrolyte. In view of these merits, the commercial AC-based aqueous SC device with this AWIS electrolyte could present a high cell voltage of $2.2 \mathrm{~V}$. Afterwards, Xiao et al. exhibited an optimum LiTFSI/ $\mathrm{H}_{2} \mathrm{O} /(\mathrm{ACN})_{3.5}$ electrolyte with the best comprehensive performance via designing a series of organic/water hybrid electrolyte systems [94]. Benefiting from the low water electrolysis activity, this electrolyte displayed an ESW as wide as $3.26 \mathrm{~V}$ (Fig. 8c). Besides, this resultant carbon-based symmetric SC device operating in this WIS electrolyte was able to exhibit a favorable maximum cell voltage of $2.4 \mathrm{~V}$ (Fig. 8d).

The other challenge is the high cost of WIS-based electrolyte. In general, the traditional WIS electrolytes are based on LiTFSI or bis(fluorosulfonyl)imide salts which are very expensive and adverse to large-scale commercial applications. To overcome this issue, it is worth searching for a series of thecost-effective soluble salts to replace the traditional LiTFSI-based electrolyte. Recently, Bu et al. reported a $17 \mathrm{~m} \mathrm{NaClO}_{4}$-based WIS electrolyte to establish a highvoltage aqueous carbon-based SC system [62]. As a proper candidate, this electrolyte delivered a superior conductivity $\left(64.2 \mathrm{mS} \mathrm{cm}^{-1}\right)$ which was better than the traditional WIS electrolyte $\left(8.2 \mathrm{mS} \mathrm{cm}^{-1}\right)$. DFT-MD simulations confirmed that the majority of water molecules are coordinated with $\mathrm{Na}^{+}$ions through the Lewis-basic oxygen. When an aqueous $\mathrm{SC}$ device was composed of the commercial AC electrodes and the $\mathrm{NaClO}_{4}$-based WIS electrolyte, a 2.3-V cell voltage could be achieved. In addition, an eco-friendly and cost-effective HCOOK-based WIS electrolyte was also proposed, which could reach an extremely high concentration of $40 \mathrm{M}$ (mol $L^{-1}$, where $L$ is the volume of the mixed solution) at ambient temperature [97]. Compared to other WIS electrolytes, this electrolyte owns more negative stable potential and higher ionic conductivity. Therefore, the ESW of this electrolyte could reach $4 \mathrm{~V}$ (vs. $\mathrm{Ag} / \mathrm{AgCl}$ ) in a threeelectrode system. When this electrolyte was utilized in an intact AC-based SC system, the built device could deliver a maximum cell voltage of $2.4 \mathrm{~V}$.

To sum up, it is straightforward and convenient to design the high-voltage aqueous SCs via constructing the WIS electrolyte. Because of the simple operation procedure and admirable performance, this method has drawn considerable interests for the past years. However, the inferior physicochemical features (e.g., conductivity and viscosity) and exorbitant price are still impeding the further development of the WIS electrolytes. Hence, enormous efforts should be made to optimize the WIS electrolyte in the future.

\section{Designing Aqueous Asymmetric Supercapacitors}

Due to the superior electrochemical performance and high economic benefit, aqueous symmetric SCs, represented by aqueous carbon-based symmetric SCs, are dominated in the commercial energy storage filed [13, 23]. Nevertheless, the intrinsic properties (e.g., low capacitance) of carbonbased electrode materials are the major drawbacks that hinder the prospect of this device. To address this challenge, 
asymmetric design is recognized as a promising approach to construct the high-voltage aqueous SCs [53]. Owing to the advantages of low cost and simple operation, this strategy seems to be suitable for the large-scale commercial applications. In contrast with the conventional aqueous symmetric SCs, aqueous ASC device applies a hybrid system consisted of an electric double-layer capacitive electrode and a pseudo-capacitive electrode as the energy source (Fig. 9a) [26]. Benefiting from this unique structure, aqueous ASCs normally deliver excellent electrochemical performances. During the charge and discharge process, this configuration can take full advantage of the stable potential range of two electrodes and suppress the water electrolysis process, in favor of breaking through the over-potential barrier and enlarging the cell voltage [78]. For instance, it is reported that the cell voltage of aqueous symmetric SC device is only limited to $1.2 \mathrm{~V}$, whereas the ASC system can yield a maximum cell voltage as high as $2 \mathrm{~V}$ [53].

In view of the above merits, designing aqueous ASCs have attracted tremendous attentions to expand the cell voltage of SCs in the past years. For example, Zhang et al. assembled an advanced aqueous ASC device consisted of supramolecular network-Prussian blue (CSN-PB)/ $\mathrm{MnO}_{2}$ composite as cathode and activated carbon as anode (Fig. 9b) [20]. Profiting from synergistic effect of the constituent components, this device can deliver an expanded cell voltage $(2.4 \mathrm{~V})$, high energy density ( $46.13 \mathrm{Wh} \mathrm{kg}^{-1}$ at $1200 \mathrm{~W} \mathrm{~kg}^{-1}$ ), and stable cyclic stability $(85.5 \%$ capacitance retention after 20,000 cycles) (Fig. 9c-e). Similarly, Ghoah et al. constructed an aqueous $\mathrm{ASC}$ device comprised of $\mathrm{MnO}_{2} /$ Vertical graphene nanosheets (VGN) and $\mathrm{Fe}_{2} \mathrm{O}_{3} / \mathrm{VGN}$ as positive and negative electrodes, respectively [98]. When this as-fabricated device operated in $1 \mathrm{M} \mathrm{NaClO}_{4}$ electrolyte, a high cell voltage of $2.6 \mathrm{~V}$ can be achieved. In addition, a 2.0-V wearable aqueous SC system consisted of poly(3,4-ethylenedioxythio-phene):poly(styrenesulfonic acid) (PEDOT:PSS)/ $\mathrm{Fe}_{2} \mathrm{O}_{3}$-CNTs/CFC as negative electrode and PEDOT:PSS/ $\mathrm{CoFe}_{2} \mathrm{O}_{4} / \mathrm{CFC}$ as positive electrode was also acquired by the asymmetric design [15].

In spite of these great achievements, there are still two factors that restrict the prospect of high-voltage aqueous ASCs. One is the charge of two electrodes. In terms of most aqueous ASC systems, the charge of the positive and negative electrode must be balanced to ensure the cycling stability. The other is the stability of electrode materials. During the charge/discharge process, pseudo-capacitive electrode (a) Mostly electric double-layer Redox (faradic) reactions (non-faradic or electrostatic) with or without non-faradic absorption/desportion

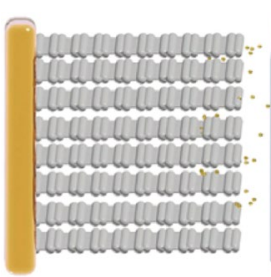

(c)



(b)



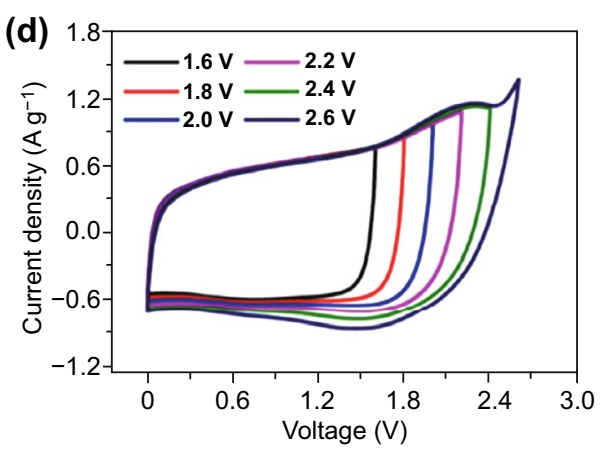

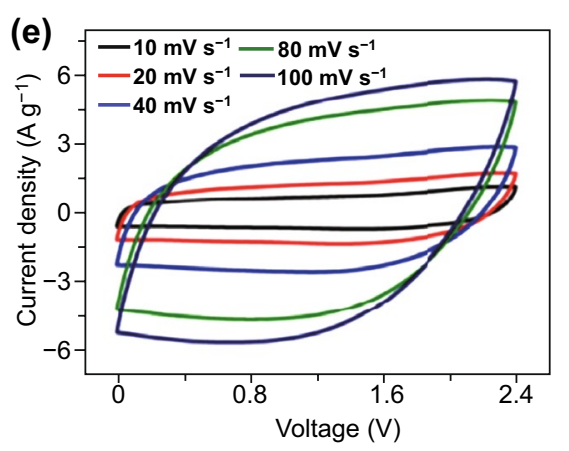

Fig. 9 a Schematic of an ASC device. Adapted with permission from Ref. [50]. b Schematic illustration of the CSN-PB/MnO $2 / / A C$ device configuration. $\mathbf{c} \mathrm{CV}$ curves of the $\mathrm{CSN}-\mathrm{PB} / \mathrm{MnO}_{2} / / \mathrm{AC}$ device in different potential range at a scan rate of $10 \mathrm{mV} \mathrm{s}^{-1}$. d CV curves of the CSN-PB/ $\mathrm{MnO}_{2} / / \mathrm{AC}$ device at varied scan rates from 10 to $100 \mathrm{mV} \mathrm{s}^{-1}$ in a potential range of $0-2.4 \mathrm{~V}$. e CV curves of the $\mathrm{CSN}-\mathrm{PB} / \mathrm{MnO} / / / \mathrm{AC}$ device at varied scan rates from 10 to $100 \mathrm{mV} / \mathrm{s}$. Adapted with permissions from Ref. [20] 
normally stores charge via redox reactions. Along with the occurrence of reactions, asymmetric device often suffers from the inferior cycling stability originating from the rapid degradation of electrode materials. Aiming at these challenges above, it is urgent to take efficacious measures to overcome these problems, such as fabricating the carbon layer coating materials and balancing the charges between two electrodes [11, 53]. Moreover, the research hot spot of aqueous SCs mainly focuses on designing high capacitance device, and the number of studies about constructing highvoltage aqueous SCs is still scarce in the last few years. Therefore, a great deal of attempts should be made to boost the cell voltage of aqueous SCs in the future.

\section{Conclusions and Future Perspectives}

To the best of knowledge, the insufficient energy density is a major drawback of aqueous SCs, which may significantly restrict their large-scale applications. Based on the equation of $E=0.5 C V^{2}$, it is evident that boosting the cell voltage can efficiently enhance the energy density. In this mini review, we summarize the recent advances about boosting the cell voltage of aqueous SCs, which are achieved by modifying the electrode materials, optimizing the electrolyte properties, and designing aqueous ASCs, separately. From the viewpoint of electrodes, the generic approaches include doping alkali cations, modulating the electrode mass ratio and optimizing the surface charge density, respectively. In principle, doping alkali cations into electrodes can effectively inhibit electrocatalytic activity of electrode materials and improve the over-potential of HER/OER, thereby widening of ESW of aqueous media, whereas the mechanisms of the latter two methods mainly depend on eliminating the limitation of $P_{0 \mathrm{~V}}$ and improving the utilization efficiency of electrode potential range. From the viewpoint of electrolytes, the universal pathways contain adjusting the appropriate $\mathrm{pH}$ level, introducing redox mediators and constructing "water-insalt" electrolyte, respectively. The mechanism of aforesaid pathways is suppressing the water electrolysis activity. In addition, the mechanism of designing ASCs is enhancing the potential range utilization of both electrodes. Although great achievements have been obtained for constructing high-voltage aqueous SCs in recent years, there are still several bottlenecks to break through in the subsequent working process. On the basis of relevant studies, we summarize the as-following challenges and future development trends:

1. The diversity of doping particles. Except for the alkali cations, doping other categories particles (e.g., alkaline earth cations, halide ions, and acid group cations) into electrode materials is also worthwhile exploring in the future.

2. Simplifying the operation procedures of modification pathways. Taking modulating the electrode mass ratio for an example, due to the lack of definite theoretical analysis methods, it is time-consuming and complicated to obtain the optimal electrode mass ratio through various experimental gradient designs. Therefore, it is urgent to take smart and accurate measures to simplify the experimental process.

3. Eliminating the adverse influences of self-discharge behavior. In the aforesaid sections, we have discussed that applying ECI technique and constructing redox electrolytes normally suffer from the self-discharge effect, leading to the poor electrochemical ability. As a consequence, how to suppress the self-discharge behavior is still a challenging research in the subsequent process.

4. Optimizing the features of WIS electrolyte. Although constructing WIS electrolyte is more efficient and straightforward to widen the cell voltage of aqueous SCs, the intrinsic shortcomings (e g., low conductivity, high viscosity, and expensive price) of traditional LiTFSI salt are the major drawbacks to hinder its commercial applications. Hence, it is desirable to optimize the traditional LiTFSI-based electrolytes and search for the cheap substitutes for LiTFSI salt.

5. Combining the merits of modifying electrodes and electrolytes. In common, adopting single strategy from electrode or electrolyte aspect cannot satisfy the demands of high-voltage aqueous SCs. Consequently, it is worth simultaneously optimizing the properties of electrodes and electrolytes to boost the cell voltage of aqueous SCs.

6. Improving the cycling stability of electrode materials. For the most aqueous ASC devices, the electrode materials often suffer from the stability issue during the repeated cyclic process, thereby causing the inferior electrochemical performance. Hence, some efficacious measures should be taken to solve this problem, such as designing nano-structure electrodes and introducing carbon-based layer coating materials.

In summary, the purpose of this mini review is expected to attract more attentions to the relevant studies about constructing high-voltage aqueous SCs and provide referencing 
values for other researchers, thereby promoting the further progress of aqueous SCs with high energy density.

Acknowledgements This work was financially supported by research grants from the Natural Science Foundation of China (51702032), Natural Science Foundation of Chongqing (cstc2018jcyjAX0375), Fundamental Research Funds for the Central Universities (2019CDXYDL0007), and Key Innovation Project for Clinical Technology of the Second Affiliated Hospital of Army Medical University (2018JSLC0025).

Open Access This article is licensed under a Creative Commons Attribution 4.0 International License, which permits use, sharing, adaptation, distribution and reproduction in any medium or format, as long as you give appropriate credit to the original author(s) and the source, provide a link to the Creative Commons licence, and indicate if changes were made. The images or other third party material in this article are included in the article's Creative Commons licence, unless indicated otherwise in a credit line to the material. If material is not included in the article's Creative Commons licence and your intended use is not permitted by statutory regulation or exceeds the permitted use, you will need to obtain permission directly from the copyright holder. To view a copy of this licence, visit http://creativecommons.org/licenses/by/4.0/.

\section{References}

1. Q. Gou, C. Li, W. Zhong, X. Zhang, Q. Dong, C. Lei, Hierarchical structured porous $\mathrm{N}$-doped carbon coating $\mathrm{MnO}$ microspheres with enhanced electrochemical performances as anode materials for lithium-ion batteries. Electrochim. Acta 296, 730-737 (2019). https://doi.org/10.1016/j.elect acta.2018.11.104

2. Q. Gou, C. Li, X. Zhang, B. Zhang, D. Huang, C. Lei, Facile synthesis of porous ternary $\mathrm{MnTiO}_{3} / \mathrm{TiO}_{2} / \mathrm{C}$ composite with enhanced electrochemical performance as anode materials for lithium ion batteries. Energy Technol. 7, 1800861 (2019). https://doi.org/10.1002/ente.201800761

3. M. Li, J. Xue, Integrated synthesis of nitrogen-doped mesoporous carbon from melamine resins with superior performance in supercapacitors. J. Phys. Chem. C 118, 25072517 (2014). https://doi.org/10.1021/jp410198r

4. M. Li, Z. Tang, M. Leng, J. Xue, Flexible solid-state supercapacitor based on graphene-based hybrid films. Adv. Funct. Mater. 24, 7495-7502 (2014). https://doi.org/10.1002/ adfm.201402442

5. L. Fan, B. Zhu, P.-C. Su, C. He, Nanomaterials and technologies for low temperature solid oxide fuel cells: recent advances, challenges and opportunities. Nano Energy 45, 148-176 (2018). https://doi.org/10.1016/j.nanoen.2017.12.044

6. W. Guo, C. Yu, S. Li, Z. Wang, J. Yu, H. Huang, J. Qiu, Strategies and insights towards the intrinsic capacitive properties of $\mathrm{MnO}_{2}$ for supercapacitors: Challenges and perspectives. Nano Energy 57, 459-472 (2019). https://doi.org/10.1016/j.nanoe n.2018.12.015
7. C. Zhong, Y. Deng, W. Hu, J. Qiao, L. Zhang, J. Zhang, A review of electrolyte materials and compositions for electrochemical supercapacitors. Chem. Soc. Rev. 44, 7484-7539 (2015). https://doi.org/10.1039/c5cs00303b

8. J. Sun, Y. Huang, Y.N. Sze Sea, Q. Xue, Z. Wang et al., Recent progress of fiber-shaped asymmetric supercapacitors. Mater. Today Energy 5, 1-14 (2017). https://doi.org/10.1016/j.mtene r.2017.04.007

9. W. Zuo, R. Li, C. Zhou, Y. Li, J. Xia, J. Liu, Battery-supercapacitor hybrid devices: recent progress and future prospects. Adv. Sci. 4, 1600539 (2017). https://doi.org/10.1002/ advs.201600539

10. R.B. Choudhary, S. Ansari, B. Purty, Robust electrochemical performance of polypyrrole (PPy) and polyindole (PIn) based hybrid electrode materials for supercapacitor application: a review. J. Energy Storage 29, 101302 (2020). https:// doi.org/10.1016/j.est.2020.101302

11. T. Wang, H.C. Chen, F. Yu, X.S. Zhao, H. Wang, Boosting the cycling stability of transition metal compounds-based supercapacitors. Energy Storage Mater. 16, 545-573 (2019). https ://doi.org/10.1016/j.ensm.2018.09.007

12. M.A.A. MohdAbdah, N.H.N. Azman, S. Kulandaivalu, Y. Sulaiman, Review of the use of transition-metal-oxide and conducting polymer-based fibres for high-performance supercapacitors. Mater. Des. 186, 108199 (2020). https://doi. org/10.1016/j.matdes.2019.108199

13. Z. Yang, J. Tian, Z. Yin, C. Cui, W. Qian, F. Wei, Carbon nanotube- and graphene-based nanomaterials and applications in high-voltage supercapacitor: a review. Carbon 141, 467-480 (2019). https://doi.org/10.1016/j.carbon.2018.10.010

14. L. Peng, X. Peng, B. Liu, C. Wu, Y. Xie, G. Yu, Ultrathin twodimensional $\mathrm{MnO}_{2}$ /graphene hybrid nanostructures for highperformance, flexible planar supercapacitors. Nano Lett. 13, 2151-2157 (2013). https://doi.org/10.1021/nl400600x

15. K. Song, X. Wang, J. Wang, B. Zhang, R. Yang, Bifunctional conducting polymer coated $\mathrm{CoFe}_{2} \mathrm{O}_{4}$ core-shell nanolayer on carbon fiber cloth for $2.0 \mathrm{v}$ wearable aqueous supercapacitors. Chem. Sel. 4, 1685-1695 (2019). https://doi.org/10.1002/ slct.201900069

16. I. Shown, A. Ganguly, L.-C. Chen, K.-H. Chen, Conducting polymer-based flexible supercapacitor. Energy Sci.: Eng. 3, 2-26 (2015). https://doi.org/10.1002/ese3.50

17. X.-Y. Yu, L. Yu, X.W.D. Lou, Metal sulfide hollow nanostructures for electrochemical energy storage. Adv. Energy Mater. 6, 1501333 (2016). https://doi.org/10.1002/aenm.201501333

18. X. Rui, H. Tan, Q. Yan, Nanostructured metal sulfides for energy storage. Nanoscale 6, 9889-9924 (2014). https://doi. org/10.1039/c4nr03057e

19. L. Demarconnay, E. Raymundo-Piñero, F. Béguin, Adjustment of electrodes potential window in an asymmetric carbon/ $\mathrm{MnO}_{2}$ supercapacitor. J. Power Sources 196, 580-586 (2011). https ://doi.org/10.1016/j.jpowsour.2010.06.013

20. G. Zhang, H. Yao, F. Zhang, Z. Gao, Q. Li, Y. Yang, X. Lu, A high over-potential binder-free electrode constructed of Prussian blue and $\mathrm{MnO}_{2}$ for high performance aqueous 
supercapacitors. Nano Res. 12, 1061-1069 (2019). https:// doi.org/10.1007/s12274-019-2347-2

21. M. Zhang, Y. Li, Z. Shen, "Water-in-salt" electrolyte enhanced high voltage aqueous supercapacitor with all-pseudocapacitive metal-oxide electrodes. J. Power Sources 414, 479-485 (2019). https://doi.org/10.1016/j.jpowsour.2019.01.037

22. S.-W. Zhang, B.-S. Yin, X.-X. Liu, D.-M. Gu, H. Gong, Z.-B. Wang, A high energy density aqueous hybrid supercapacitor with widened potential window through multi approaches. Nano Energy 59, 41-49 (2019). https://doi.org/10.1016/j. nanoen.2019.02.001

23. M. Yu, Z. Wang, H. Zhang, P. Zhang, T. Zhang, X. Lu, X. Feng, Amino functionalization optimizes potential distribution: a facile pathway towards high-energy carbon-based aqueous supercapacitors. Nano Energy 65, 103987 (2019). https:// doi.org/10.1016/j.nanoen.2019.103987

24. D. Xiao, Q. Wu, X. Liu, Q. Dou, L. Liu, B. Yang, H. Yu, Aqueous symmetric supercapacitors with carbon nanorod electrodes and water-in-salt electrolyte. ChemElectroChem 6, 439-443 (2019). https://doi.org/10.1002/celc.201801342

25. D.R. MacFarlane, N. Tachikawa, M. Forsyth, J.M. Pringle, P.C. Howlett et al., Energy applications of ionic liquids. Energy Environ. Sci. 7, 232-250 (2014). https://doi. org/10.1039/c3ee42099j

26. M. Yu, Y. Lu, H. Zheng, X. Lu, New insights into the operating voltage of aqueous supercapacitors. Chem. Eur. J. 24, 3639-3649 (2018). https://doi.org/10.1002/chem.201704420

27. W. Deng, X. Wang, C. Liu, C. Li, J. Chen, N. Zhu, R. Li, M. Xue, Li/K mixed superconcentrated aqueous electrolyte enables high-performance hybrid aqueous supercapacitors. Energy Storage Mater. 20, 373-379 (2019). https://doi. org/10.1016/j.ensm.2018.10.023

28. T. Qin, H. Chen, Y. Zhang, X. Chen, L. Liu et al., Modulating surface chemistry of heteroatom-rich micropore carbon cloth electrode for aqueous $2.1 \mathrm{~V}$ high-voltage window all-carbon supercapacitor. J. Power Sources 431, 232-238 (2019). https ://doi.org/10.1016/j.jpowsour.2019.05.004

29. Y. Han, Z. Lai, Z. Wang, M. Yu, Y. Tong, X. Lu, Designing carbon based supercapacitors with high energy density: a summary of recent progress. Chem. 24, 7312-7329 (2018). https ://doi.org/10.1002/chem.201705555

30. M. Vijayakumar, D.S. Rohita, T.N. Rao, M. Karthik, Electrode mass ratio impact on electrochemical capacitor performance. Electrochim. Acta 298, 347-359 (2019). https://doi. org/10.1016/j.electacta.2018.12.034

31. N. Jabeen, A. Hussain, Q. Xia, S. Sun, J. Zhu, H. Xia, Highperformance $2.6 \mathrm{~V}$ aqueous asymmetric supercapacitors based on in situ formed $\mathrm{Na}_{0.5} \mathrm{MnO}_{2}$ nanosheet assembled nanowall arrays. Adv. Mater. 29, 1700804 (2017). https://doi. org/10.1002/adma.201700804

32. K.-C. Ho, L.-Y. Lin, A review of electrode materials based on core-shell nanostructures for electrochemical supercapacitors. J. Mater. Chem. A 7, 3516-3530 (2019). https://doi. org/10.1039/c8ta11599k
33. Z. Dai, C. Peng, J.H. Chae, K.C. Ng, G.Z. Chen, Cell voltage versus electrode potential range in aqueous supercapacitors. Sci. Rep. 5, 9854 (2015). https://doi.org/10.1038/srep09854

34. H. Wang, C. Xu, Y. Chen, Y. Wang, $\mathrm{MnO}_{2}$ nanograsses on porous carbon cloth for flexible solid-state asymmetric supercapacitors with high energy density. Energy Storage Mater. 8, 127-133 (2017). https://doi.org/10.1016/j.ensm.2017.05.007

35. D. Zhai, B. Li, H. Du, G. Gao, L. Gan, Y. He, Q. Yang, F. Kang, The preparation of graphene decorated with manganese dioxide nanoparticles by electrostatic adsorption for use in supercapacitors. Carbon 50, 5034-5043 (2012). https://doi. org/10.1016/j.carbon.2012.06.033

36. J. Yan, S. Li, B. Lan, Y. Wu, P.S. Lee, Rational design of nanostructured electrode materials toward multifunctional supercapacitors. Adv. Funct. Mater. 30, 1902564 (2019). https://doi. org/10.1002/adfm.201902564

37. N. Jabeen, Q. Xia, S.V. Savilov, S.M. Aldoshin, Y. Yu, H. Xia, Enhanced pseudocapacitive performance of $\alpha-\mathrm{MnO}_{2}$ by cation preinsertion. ACS Appl. Mater. Interfaces 8, 33732-33740 (2016). https://doi.org/10.1021/acsami.6b12518

38. G. Liu, C. Kang, J. Fang, L. Fu, H. Zhou, Q. Liu, $\mathrm{MnO}_{2}$ nanosheet-coated $\mathrm{Co}_{3} \mathrm{O}_{4}$ complex for $1.4 \mathrm{~V}$ extra-high voltage supercapacitors electrode material. J. Power Sources 431, 48-54 (2019). https://doi.org/10.1016/j.jpowsour.2019.05.053

39. T. Xiong, W.S.V. Lee, J. Xue, $\mathrm{K}^{+}$-intercalated $\mathrm{MnO}_{2}$ electrode for high performance aqueous supercapacitor. ACS Appl. Energy Mater. 1, 5619-5626 (2018). https://doi.org/10.1021/ acsaem.8b01160

40. Q.-Z. Gou, C. Li, X.-Q. Zhang, B. Zhang, S.-R. Zou et al., Facile synthesis of porous $\mathrm{Mn}_{2} \mathrm{O}_{3} / \mathrm{TiO}_{2}$ microspheres as anode materials for lithium-ion batteries with enhanced electrochemical performance. J. Mater. Sci.: Mater. Electron. 29, 16064 16073 (2018). https://doi.org/10.1007/s10854-018-9695-7

41. H. Xia, X. Zhu, J. Liu, Q. Liu, S. Lan et al., A monoclinic polymorph of sodium birnessite for ultrafast and ultrastable sodium ion storage. Nat. Commun. 9, 5100 (2018). https:// doi.org/10.1038/s41467-018-07595-y

42. B. Lin, X. Zhu, L. Fang, X. Liu, S. Li et al., Birnessite nanosheet arrays with high $\mathrm{K}$ content as a high-capacity and ultrastable cathode for K-ion batteries. Adv. Mater. 31, 1900060 (2019). https://doi.org/10.1002/adma.201900060

43. T. Xiong, T.L. Tan, L. Lu, W.S. Lee, J. Xue, Harmonizing energy and power density toward $2.7 \mathrm{~V}$ asymmetric aqueous supercapacitor. Adv. Energy Mater. 8, 1702630 (2018). https ://doi.org/10.1002/aenm.201702630

44. Y. Zhou, Z. Zhu, C. Zhao, K. Zhang, B. Wang, C. Zhao, G. Chen, Reclaimed carbon fiber-based $2.4 \mathrm{~V}$ aqueous symmetric supercapacitors. ACS Sustain. Chem. Eng. 7, 5095-5102 (2019). https://doi.org/10.1021/acssuschemeng.8b05951

45. P. Hao, Z. Zhao, Y. Leng, J. Tian, Y. Sang et al., Graphenebased nitrogen self-doped hierarchical porous carbon aerogels derived from chitosan for high performance supercapacitors. Nano Energy 15, 9-23 (2015). https://doi.org/10.1016/j.nanoe n.2015.02.035

46. Z. Tang, G. Zhang, H. Zhang, L. Wang, H. Shi, D. Wei, H. Duan, MOF-derived N-doped carbon bubbles on carbon 
tube arrays for flexible high-rate supercapacitors. Energy Storage Mater. 10, 75-84 (2018). https://doi.org/10.1016/j. ensm.2017.08.009

47. Y. Jiao, Y. Zheng, K. Davey, S.-Z. Qiao, Activity origin and catalyst design principles for electrocatalytic hydrogen evolution on heteroatom-doped graphene. Nat. Energy 1, 16130 (2016). https://doi.org/10.1038/nenergy.2016.130

48. X. Wu, B. Huang, Q. Wang, Y. Wang, Wide potential and high energy density for an asymmetric aqueous supercapacitor. J. Mater. Chem. A 7, 19017-19025 (2019). https://doi. org/10.1039/c9ta06428a

49. Q. Dou, C. Lian, S. Lei, J. Chen, H. Liu, X. Yan, Silica-grafted ionic liquid for maximizing the operational voltage of electrical double-layer capacitors. Energy Storage Mater. 18, 253259 (2019). https://doi.org/10.1016/j.ensm.2018.09.004

50. S. Zheng, Z.-S. Wu, S. Wang, H. Xiao, F. Zhou, C. Sun, X. Bao, H.-M. Cheng, Graphene-based materials for highvoltage and high-energy asymmetric supercapacitors. Energy Storage Mater. 6, 70-97 (2017). https://doi.org/10.1016/j. ensm.2016.10.003

51. Z. Weng, F. Li, D.W. Wang, L. Wen, H.M. Cheng, Controlled electrochemical charge injection to maximize the energy density of supercapacitors. Angew. Chem. Int. Ed. 52, 3810-3813 (2013). https://doi.org/10.1002/anie.201209259

52. J. Li, J. Tang, J. Yuan, K. Zhang, Y. Sun, H. Zhang, L.-C. Qin, Enlarging energy density of supercapacitors using unequal graphene electrodes and ionic liquid electrolyte. Electrochim. Acta 258, 1053-1058 (2017). https://doi.org/10.1016/j.elect acta.2017.11.157

53. Y. Shao, M.F. El-Kady, J. Sun, Y. Li, Q. Zhang et al., Design and mechanisms of asymmetric supercapacitors. Chem. Rev. 118, 9233-9280 (2018). https://doi.org/10.1021/acs.chemr ev. 8 b00252

54. J. Yan, Z. Fan, W. Sun, G. Ning, T. Wei et al., Advanced asymmetric supercapacitors based on $\mathrm{Ni}(\mathrm{OH})_{2} / \mathrm{Graphene}$ and porous graphene electrodes with high energy density. Adv. Funct. Mater. 22, 2632-2641 (2012). https://doi.org/10.1002/ adfm.201102839

55. E.G. Calvo, F. Lufrano, A. Arenillas, A. Brigandì, J.A. Menéndez, P. Staiti, Effect of unequal load of carbon xerogel in electrodes on the electrochemical performance of asymmetric supercapacitors. J. Appl. Electrochem. 44, 481-489 (2014). https://doi.org/10.1007/s10800-013-0656-9

56. X. Wang, D. Gu, J. Yu, H. Jiang, H. Sun, L. Wang, L. Shen, Accurate modulation of mass ratio on electrodes of ruthenium oxide//polyaniline supercapacitor for improving energy density. J. Electrochem. Soc. 166, A1884-A1892 (2019). https:// doi.org/10.1149/2.0741910jes

57. A.A. Zakhidov, D.-S. Suh, A.A. Kuznetsov, J.N. Barisci, E. Muñoz et al., Electrochemically tuned properties for electrolyte-free carbon nanotube sheets. Adv. Funct. Mater. 19, 2266-2272 (2009). https://doi.org/10.1002/adfm.200900253

58. Z. Lin, X. Yan, J. Lang, R. Wang, L.-B. Kong, Adjusting electrode initial potential to obtain high-performance asymmetric supercapacitor based on porous vanadium pentoxide nanotubes and activated carbon nanorods. J. Power Sources 279, 358-364 (2015). https://doi.org/10.1016/j.jpowsour.2015.01.034

59. M. Yu, D. Lin, H. Feng, Y. Zeng, Y. Tong, X. Lu, Boosting the energy density of carbon-based aqueous supercapacitors by optimizing the surface charge. Angew. Chem. Int. Ed. 56, 5454-5459 (2017). https://doi.org/10.1002/anie.201701737

60. X. Guo, B. Feng, L. Gai, J. Zhou, Reduced graphene oxide/ polymer dots-based flexible symmetric supercapacitors delivering an output potential of $1.7 \mathrm{~V}$ with electrochemical charge injection. Electrochim. Acta 293, 399-407 (2019). https://doi. org/10.1016/j.electacta.2018.10.057

61. J. Wang, S.P. Feng, Y. Yang, N.Y. Hau, M. Munro, E. FerreiraYang, G. Chen, "Thermal Charging" phenomenon in electrical double layer capacitors. Nano Lett. 15, 5784-5790 (2015). https://doi.org/10.1021/acs.nanolett.5b01761

62. X. Bu, L. Su, Q. Dou, S. Lei, X. Yan, A low-cost "water-insalt" electrolyte for a $2.3 \mathrm{~V}$ high-rate carbon-based supercapacitor. J. Mater. Chem. A 7, 7541-7547 (2019). https://doi. org/10.1039/c9ta00154a

63. Y. Huang, Y. Zeng, M. Yu, P. Liu, Y. Tong, F. Cheng, X. Lu, Recent smart methods for achieving high-energy asymmetric supercapacitors. Small Methods 2, 1700230 (2018). https:// doi.org/10.1002/smtd.201700230

64. L. Hu, T. Zhai, H. Li, Y. Wang, Redox-mediator-enhanced electrochemical capacitors: recent advances and future perspectives. ChemSusChem 12, 1118-1132 (2019). https://doi. org/10.1002/cssc. 201802450

65. A. Slesinski, C. Matei-Ghimbeu, K. Fic, F. Béguin, E. Frackowiak, Self-buffered $\mathrm{pH}$ at carbon surfaces in aqueous supercapacitors. Carbon 129, 758-765 (2018). https://doi. org/10.1016/j.carbon.2017.12.101

66. S. Sur, A.R. Kottaichamy, Z. Manzoor Bhat, M.C. Devendrachari, R. Thimmappa, M.O. Thotiyl, A pH dependent high voltage aqueous supercapacitor with dual electrolytes. Chem. Phys. Lett. 712, 160-164 (2018). https://doi.org/10.1016/j. cplett.2018.10.001

67. V. Khomenko, E. Raymundo-Piñero, F. Béguin, Optimisation of an asymmetric manganese oxide/activated carbon capacitor working at $2 \mathrm{~V}$ in aqueous medium. J. Power Sources 153, 183-190 (2006). https://doi.org/10.1016/j.jpows our.2005.03.210

68. N. Zhao, H. Fan, M. Zhang, J. Ma, W. Zhang et al., Investigating the large potential window of $\mathrm{NiCo}_{2} \mathrm{O}_{4}$ supercapacitors in neutral aqueous electrolyte. Electrochim. Acta 321, 134681 (2019). https://doi.org/10.1016/j.electacta.2019.134681

69. X. Wang, R.S. Chandrabose, Z. Jian, Z. Xing, X. Ji, A 1.8 $\mathrm{V}$ aqueous supercapacitor with a bipolar assembly of ionexchange membranes as the separator. J. Electrochem. Soc. 163, A1853-A1858 (2016). https://doi.org/10.1149/2.03116 09jes

70. M. Tian, J. Wu, R. Li, Y. Chen, D. Long, Fabricating a highenergy-density supercapacitor with asymmetric aqueous redox additive electrolytes and free-standing activated-carbon-felt electrodes. Chem. Eng. J. 363, 183-191 (2019). https://doi. org/10.1016/j.cej.2019.01.070 
71. K.V. Sankar, Y. Seo, S.C. Lee, S. Chan Jun, Redox additiveimproved electrochemically and structurally robust binder-free nickel pyrophosphate nanorods as superior cathode for hybrid supercapacitors. ACS Appl. Mater. Interfaces 10, 8045-8056 (2018). https://doi.org/10.1021/acsami.7b19357

72. S.T. Senthilkumar, R.K. Selvan, J.S. Melo, Redox additive/ active electrolytes: a novel approach to enhance the performance of supercapacitors. J. Mater. Chem. A 1, 12386-12394 (2013). https://doi.org/10.1039/c3ta11959a

73. B. Akinwolemiwa, C. Peng, G.Z. Chen, Redox electrolytes in supercapacitors. J. Electrochem. Soc. 162, A5054-A5059 (2015). https://doi.org/10.1149/2.0111505jes

74. B. Evanko, S.W. Boettcher, S.J. Yoo, G.D. Stucky, Redoxenhanced electrochemical capacitors: status, opportunity, and best practices for performance evaluation. ACS Energy Lett. 2, 2581-2590 (2017). https://doi.org/10.1021/acsenergyl ett. $7 \mathrm{~b} 00828$

75. T. Zhai, S. Sun, X. Liu, C. Liang, G. Wang, H. Xia, Achieving insertion-like capacity at ultrahigh rate via tunable surface pseudocapacitance. Adv. Mater. 30, 1706640 (2018). https:// doi.org/10.1002/adma.201706640

76. S.E. Chun, B. Evanko, X. Wang, D. Vonlanthen, X. Ji, G.D. Stucky, S.W. Boettcher, Design of aqueous redox-enhanced electrochemical capacitors with high specific energies and slow self-discharge. Nat. Commun. 6, 7818 (2015). https:// doi.org/10.1038/ncomms8818

77. Q. Li, M. Haque, V. Kuzmenko, N. Ramani, P. Lundgren, A.D. Smith, P. Enoksson, Redox enhanced energy storage in an aqueous high-voltage electrochemical capacitor with a potassium bromide electrolyte. J. Power Sources 348, 219-228 (2017). https://doi.org/10.1016/j.jpowsour.2017.02.082

78. J.Y. Hwang, M. Li, M.F. El-Kady, R.B. Kaner, Next-generation activated carbon supercapacitors: a simple step in electrode processing leads to remarkable gains in energy density. Adv. Funct. Mater. 27, 1605745 (2017). https://doi.org/10.1002/ adfm.201605745

79. S. Sundriyal, V. Shrivastav, M. Sharma, S. Mishra, A. Deep, Significantly enhanced performance of $\mathrm{rGO} / \mathrm{TiO}_{2}$ nanosheet composite electrodes based $1.8 \mathrm{~V}$ symmetrical supercapacitor with use of redox additive electrolyte. J. Alloys Compd. 790, 377-387 (2019). https://doi.org/10.1016/j.jallc om.2019.03.150

80. E. Frackowiak, M. Meller, J. Menzel, D. Gastol, K. Fic, Redox-active electrolyte for supercapacitor application. Faraday Discuss. 172, 179-198 (2014). https://doi.org/10.1039/ c4fd00052h

81. Y. Tian, J. Yan, R. Xue, B. Yi, Capacitive properties of activated carbon in $\mathrm{K}_{4} \mathrm{Fe}(\mathrm{CN})_{6}$. J. Electrochem. Soc. 158, A818A821 (2011). https://doi.org/10.1149/1.3591061

82. Y. Tian, R. Xue, X. Zhou, Z. Liu, L. Huang, Double layer capacitor based on active carbon and its improved capacitive properties using redox additive electrolyte of anthraquinonedisulphonate. Electrochim. Acta 152, 135-139 (2015). https ://doi.org/10.1016/j.electacta.2014.11.120
83. S. Roldán, M. Granda, R. Menéndez, R. Santamaría, C. Blanco, Supercapacitor modified with methylene blue as redox active electrolyte. Electrochim. Acta 83, 241-246 (2012). https ://doi.org/10.1016/j.electacta.2012.08.026

84. X.N. Sun, D. Xu, W. Hu, X.Y. Chen, Template synthesis of 2D carbon nanosheets: improving energy density of supercapacitors by dual redox additives anthraquinone-2-sulfonic acid sodium and KI. ACS Sustain. Chem. Eng. 5, 5972-5981 (2017). https://doi.org/10.1021/acssuschemeng.7b00759

85. L. Suo, O. Borodin, Y. Wang, X. Rong, W. Sun et al., "Waterin-Salt" electrolyte makes aqueous sodium-ion battery safe, green, and long-lasting. Adv. Energy Mater. 7, 1701189 (2017). https://doi.org/10.1002/aenm.201701189

86. A. Paolella, C. Faure, V. Timoshevskii, S. Marras, G. Bertoni et al., A review on hexacyanoferrate-based materials for energy storage and smart windows: challenges and perspectives. J. Mater. Chem. A 5, 18919-18932 (2017). https://doi. org/10.1039/c7ta05121b

87. J. Zheng, J.A. Lochala, A. Kwok, Z.D. Deng, J. Xiao, Research progress towards understanding the unique interfaces between concentrated electrolytes and electrodes for energy storage applications. Adv. Sci. 4, 1700032 (2017). https://doi. org/10.1002/advs.201700032

88. M. He, K. Fic, E. Frąckowiak, P. Novák, E.J. Berg, Influence of aqueous electrolyte concentration on parasitic reactions in high-voltage electrochemical, capacitors. Energy Storage Mater. 5, 111-115 (2016). https://doi.org/10.1016/j. ensm.2016.06.001

89. P. Lannelongue, R. Bouchal, E. Mourad, C. Bodin, M. Olarte, S. le Vot, F. Favier, O. Fontaine, "Water-in-Salt" for supercapacitors: a compromise between voltage, power density, energy density and stability. J. Electrochem. Soc. 165, A657A663 (2018). https://doi.org/10.1149/2.0951803jes

90. X. Zang, C. Shen, M. Sanghadasa, L. Lin, High-voltage supercapacitors based on aqueous electrolytes. ChemElectroChem 6, 976-988 (2018). https://doi.org/10.1002/celc.201801225

91. L.M. Suo, O. Borodin, T. Gao, M. Olguin, J. Ho et al., "Waterin-salt" electrolyte enables high-voltage aqueous lithiumion chemistries. Science 350, 938-943 (2015). https://doi. org/10.1126/science.aab1595

92. S.F. Lux, L. Terborg, O. Hachmöller, T. Placke, H.W. Meyer, S. Passerini, M. Winter, S. Nowak, LiTFSI stability in water and its possible use in aqueous lithium-ion batteries: ph dependency, electrochemical window and temperature stability. J. Electrochem. Soc. 160, A1694-A1700 (2013). https:// doi.org/10.1149/2.039310jes

93. L. Suo, O. Borodin, W. Sun, X. Fan, C. Yang et al., Advanced high-voltage aqueous lithium-ion battery enabled by "Waterin-Bisalt" electrolyte. Angew. Chem. Int. Ed. 55, 7136-7141 (2016). https://doi.org/10.1002/anie.201602397

94. D. Xiao, Q. Dou, L. Zhang, Y. Ma, S. Shi, S. Lei, H. Yu, X. Yan, Optimization of organic/water hybrid electrolytes for high-rate carbon-based supercapacitor. Adv. Funct. Mater. 29, 1904136 (2019). https://doi.org/10.1002/adfm.201904136 
95. A. Gambou-Bosca, D. Bélanger, Electrochemical characterization of $\mathrm{MnO}_{2}$-based composite in the presence of salt-in-water and water-in-salt electrolytes as electrode for electrochemical capacitors. J. Power Sources 326, 595-603 (2016). https://doi. org/10.1016/j.jpowsour.2016.04.088

96. Q. Dou, S. Lei, D.-W. Wang, Q. Zhang, D. Xiao et al., Safe and high-rate supercapacitors based on an "acetonitrile/water in salt" hybrid electrolyte. Energy Environ. Sci. 11, 3212-3219 (2018). https://doi.org/10.1039/c8ee01040d
97. T. Liu, L. Tang, H. Luo, S. Cheng, M. Liu, A promising waterin-salt electrolyte for aqueous based electrochemical energy storage cells with a wide potential window: highly concentrated HCOOK. Chem. Commun. 55, 12817-12820 (2019). https://doi.org/10.1039/c9cc05927j

98. S. Ghosh, S.R. Polaki, G. Sahoo, E.-M. Jin, M. Kamruddin, J.S. Cho, S.M. Jeong, Designing metal oxide-vertical graphene nanosheets structures for $2.6 \mathrm{~V}$ aqueous asymmetric electrochemical capacitor. J. Ind. Eng. Chem. 72, 107-116 (2019). https://doi.org/10.1016/j.jiec.2018.12.008 